\title{
Behavioral and Anti-inflammatory Effects of MAGL Inhibition in a Mouse Model of Inflammatory Arthritis
}

Floyd Franklin Steele III

ffs0002@mix.wvu.edu

Follow this and additional works at: https://researchrepository.wvu.edu/etd

Part of the Translational Medical Research Commons

\section{Recommended Citation}

Steele, Floyd Franklin III, "Behavioral and Anti-inflammatory Effects of MAGL Inhibition in a Mouse Model of Inflammatory Arthritis" (2019). Graduate Theses, Dissertations, and Problem Reports. 4114.

https://researchrepository.wvu.edu/etd/4114

This Thesis is protected by copyright and/or related rights. It has been brought to you by the The Research Repository @ WVU with permission from the rights-holder(s). You are free to use this Thesis in any way that is permitted by the copyright and related rights legislation that applies to your use. For other uses you must obtain permission from the rights-holder(s) directly, unless additional rights are indicated by a Creative Commons license in the record and/ or on the work itself. This Thesis has been accepted for inclusion in WVU Graduate Theses, Dissertations, and Problem Reports collection by an authorized administrator of The Research Repository @ WVU. For more information, please contact researchrepository@mail.wvu.edu. 


\title{
Behavioral and Anti-inflammatory Effects of MAGL Inhibition in a Mouse Model of Inflammatory Arthritis
}

\author{
Floyd F. Steele \\ Thesis submitted to the Eberly College of Arts and Sciences at \\ West Virginia University \\ in partial fulfillment of the requirements for the degree of \\ Masters of Science in Psychology/Behavioral Neuroscience
}

Steven G. Kinsey, Ph.D., Chair

Cole M. Vonder Haar, Ph.D.

Paul R. Lockman, Ph. D.

Department of Psychology

Morgantown, WV

2019

Keywords: rheumatoid arthritis, collagen-induced arthritis, animal model, endocannabinoid, monoacylglycerol lipase

Copyright 2019 Floyd F. Steele 


\section{Abstract \\ Behavioral and Anti-inflammatory Effects of MAGL Inhibition in a Mouse Model of Inflammatory Arthritis}

\section{Floyd F. Steele}

Cannabinoids have analgesic and anti-inflammatory properties. For example, in preclinical models of acute inflammatory pain, cannabinoid receptor subtype 2 (i.e., $\mathrm{CB}_{2}$, Table 1) agonists decrease paw inflammation and resulting pain. Yet, the anti-inflammatory properties of cannabinoid receptor manipulation in chronic inflammatory pain states are unknown. Monoacylglycerol lipase (MAGL) is the primary catabolic enzyme of the endocannabinoid (i.e., endogenous cannabinoid ligand) 2-arachidonoyl glycerol (i.e., 2-AG). Compounds that inhibit MAGL indirectly increase tissue levels of 2-AG by preventing its catabolism. MAGL inhibitors demonstrate efficacy in acute models of inflammatory/rheumatic disease. Thus, in this study, the MAGL inhibitor JZL184 was tested in a mouse model of inflammatory arthritis. Behavioral, morphological, and immunological signs of collagen-induced arthritis (CIA) were quantified. JZL184 dose-dependently attenuated arthritis-induced paw swelling, per clinical scoring and paw thickness measurement. Consistent with the decreased paw swelling, JZL184 attenuated functional deficits associated with inflammatory arthritis in both a dose- and assay-dependent manner. The selective $\mathrm{CB}_{2}$ antagonist SR144528 was used to determine the necessity of $\mathrm{CB}_{2}$ activation, as an indirect mechanism for MAGL inhibition via JZL184. Paw tissue from mice subjected to CIA showed increased myeloperoxidase levels, indicating neutrophil activation by CIA. While no differences were detected in paw cytokine or chemokine levels, paw cytokines were correlated positively with paw thickness. Thus, MAGL inhibition attenuates behavioral and immune effects of inflammatory arthritis, likely via a mechanism that requires $\mathrm{CB}_{2}$ receptor activation. 
Behavioral and Anti-inflammatory Effects of MAGL Inhibition in a Mouse Model of

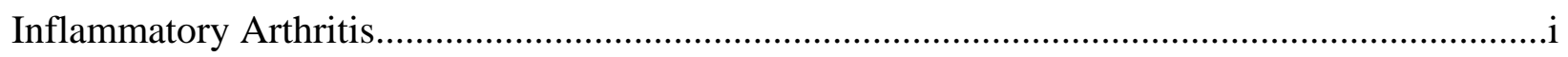

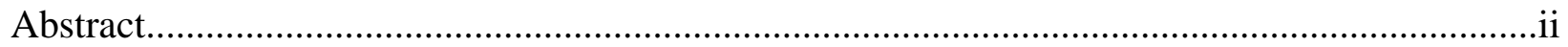

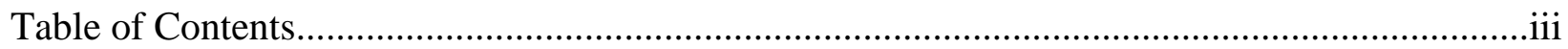

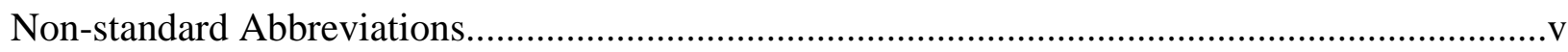

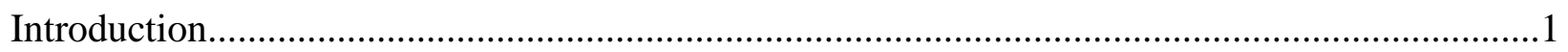

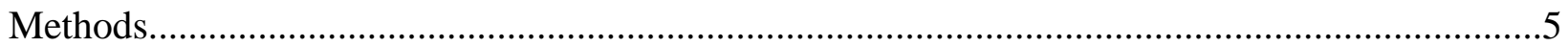

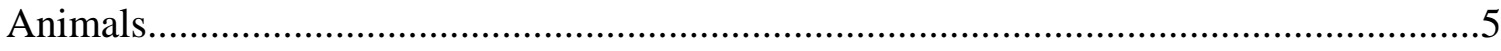

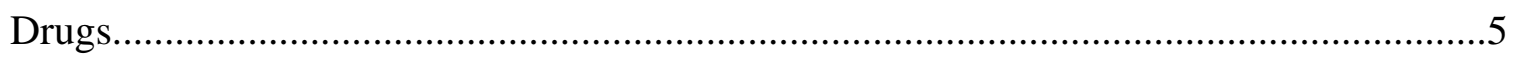

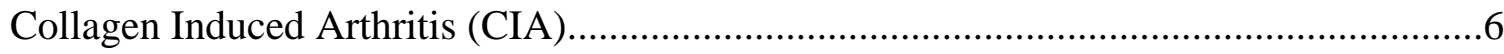

Paw Thickness and Clinical Scoring .................................................................

Behavioral Assesments.....................................................................................

Enzyme-Linked Immunosorbent Assay (ELISA) ..............................................

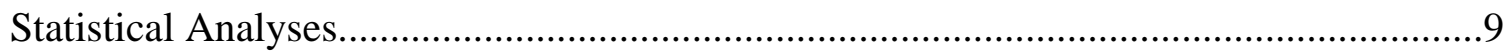

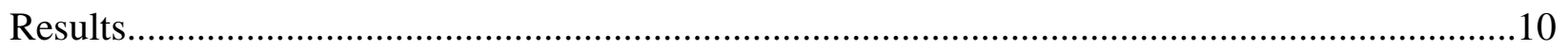

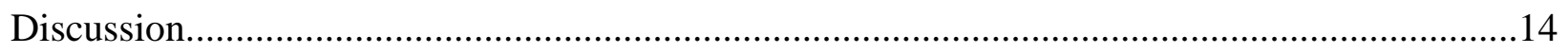

Endocannabinoid Catabolic Enzyme Inhibitors Attenuate CIA...................................14 
JZL184 Mechanisms of Action............................................................................. 15

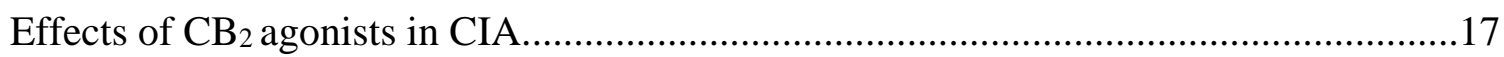

Assay Sensitivity and Behavioral Tolerance...........................................................18

Effects of JZL184 on Inflammatory Mediators........................................................19

Alternative Models of Inflammatory Arthritis.....................................................21

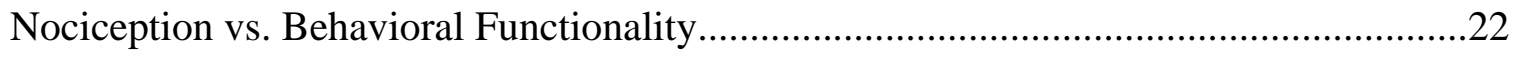

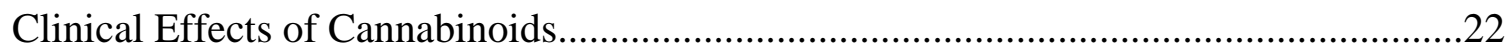

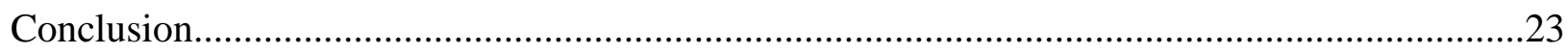

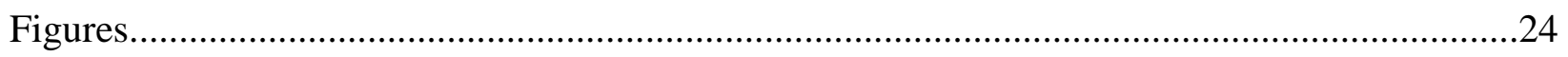

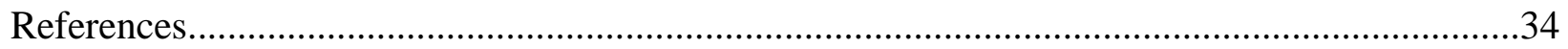

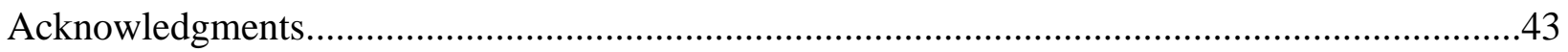


Table 1. Nonstandard abbreviations

\begin{tabular}{|c|c|}
\hline Abbreviation & Full Term \\
\hline $\mathrm{eCB}$ & Endocannabinoid \\
\hline $2-\mathrm{AG}$ & 2-arachidonoylglycerol \\
\hline $\mathrm{CB}_{1}$ & Cannabinoid receptor subtype 1 \\
\hline $\mathrm{CB}_{2}$ & Cannabinoid receptor subtype 2 \\
\hline CFA & Complete Freund's adjuvant \\
\hline CIA & Collagen induced arthritis \\
\hline DEX & Dexamethasone \\
\hline DMARDs & Disease-modifying antirheumatic drugs \\
\hline FAAH & Fatty acid amide hydrolase \\
\hline IFA & Incomplete Freund's adjuvant \\
\hline IFN- $\gamma$ & Interferon gamma \\
\hline $\mathrm{IL}$ & Interleukin \\
\hline MAGL & Monoacylglycerol lipase \\
\hline $\mathrm{MHC}$ & Major histocompatibility complex \\
\hline MPO & Myeloperoxidase \\
\hline RA & Rheumatoid arthritis \\
\hline SR2 & SR144528 \\
\hline Th1 & Type 1 helper T cells \\
\hline Th2 & Type 2 helper T cells \\
\hline THC & $\Delta^{9}$-tetrahydrocannabinol \\
\hline TNF $\alpha$ & Tumor necrosis factor alpha \\
\hline Treg & Regulatory T cells \\
\hline $\mathrm{VEH}$ & $\begin{array}{c}\text { Vehicle solution (1:1:18 parts of ethanol, } \\
\text { Kolliphor EL, and saline) }\end{array}$ \\
\hline
\end{tabular}




\section{Introduction}

Rheumatoid arthritis (RA) is an autoimmune disorder characterized by increased inflammation at the synovial joints, with associated swelling, cartilage destruction, and chronic pain (Kahlenberg \& Fox, 2011; Lee, Nassikas, \& Clauw, 2011). Although pain is a salient symptom of inflammatory arthritis, performance impairments are also observed in patients experiencing joint inflammation (Sokka, Kankainen, \& Hannonen, 2000). Current treatments for RA include both synthetic and biologic disease-modifying antirheumatic drugs (DMARDs), which vary in immunosuppressant selectivity (Gaffo, Saag, \& Curtis, 2006), and are thus more or less effective. In addition, although DMARDs may reduce RA in some patients, these drugs demonstrate tolerance, produce side effects, and are not always efficacious at reducing inflammation-associated chronic pain (Lee, 2013). Non-steroidal anti-inflammatory drugs (NSAIDS) are sometimes used to treat inflammatory arthritis, either alone or in conjunction with a DMARD, to reduce inflammatory pain, but NSAIDs have limited efficacy and their therapeutic use is limited by gastrointestinal ulceration and inflammation (Rainsford, 1999). For patients who do not respond to DMARDs or NAIDs, synthetic glucocorticoid agonists, such as prednisone, are also used clinically to suppress pro-inflammatory cytokines, such as TNF $\alpha$, IL-1 $\beta$, IL-6, and IL-17 and resulting inflammation (Coutinho \& Chapman, 2011). Despite the therapeutic potential of glucocorticoid agonists, the magnitude of nonspecific immunosuppression and endogenous glucocorticoid feedback insensitivity (e.g., Cushing's disease) they facilitate can become dangerous with prolonged use. Thus, there is a critical need to develop novel anti-inflammatory treatments for inflammatory arthritis with reduced negative sides. 
Cannabinoid receptor agonists, such as $\Delta^{9}$-tetrahydrocannabinol (THC), have been used clinically to treat symptoms of chronic and/or inflammatory pain by activating cannabinoid subtype $1\left(\mathrm{CB}_{1}\right)$ and subtype $2\left(\mathrm{CB}_{2}\right)$ receptors (Mechoulam \& Parker, 2013; Russo, 2008). $\mathrm{CB}_{1}$ is expressed throughout the body, and in high levels in neural tissues, whereas $\mathrm{CB}_{2}$ is expressed in peripheral immune cells and at low levels in the brainstem and on activated microglia and is responsible for the anti-inflammation (Donvito et al., 2017). $\mathrm{CB}_{1}$ and $\mathrm{CB}_{2}$ are expressed at synovial joints (Richardson et al., 2008), and inflammation induces $\mathrm{CB}_{2}$ expression (Gui et al., 2014). For example, $\mathrm{CB}_{2}$ receptors are upregulated on synovial lymphocytes of RA patients, and $\mathrm{CB}_{2}$ activation is associated with effector T cells that reduce autoimmunity (Jean-Gilles, Gran, \& Constantinescu, 2010). Thus, cannabinoid drugs may decrease inflammatory arthritis through a mechanism that requires $\mathrm{CB}_{2}$.

The underlying issue with nonselective CB agonist treatments is their undesirable side effects, including somnolence and cognitive impairment occurring at clinically relevant doses (Moreira, Grieb, \& Lutz, 2009). Modulation of the endogenous cannabinoid (eCB) system is an alternative strategy to direct $\mathrm{CB}$ receptor agonism that has the potential to circumvent the common side effects of cannabinoid agonists. The endocannabinoids anandamide and 2arachidonyl glycerol (2-AG) are degraded by the catabolic enzymes fatty acid amide hydroxylase (FAAH) and monoacylglycerol lipase (MAGL), respectively, although $15 \%$ of brain 2-AG is hydrolyzed by the catabolic enzymes ABHD6 and ABHD12 (Blankman, Simon, \& Cravatt, 2007). Multiple chemical compounds have been developed to selectively inhibit either enzyme, thus facilitating selective increases in either anandamide or 2-AG tone, as well as affecting behavior. For example, pharmacologic inhibition of FAAH via URB597 causes both antiinflammatory and anti-hyperalgesia profiles in mice subjected to collagen-induced arthritis (CIA) 
(Kinsey et al., 2011a). These anti-inflammation and anti-hyperalgesia of FAAH inhibition are mitigated by $\mathrm{CB}_{2}$ and $\mathrm{CB}_{1}$ agonism, respectively.

Drugs that block the catabolism of eCBs produce analgesia in multiple pain models, and at doses below those producing locomotor or cataleptic side effects (Donvito et al., 2013). For example, JZL184 inhibits MAGL with a 500-fold greater selectivity for MAGL over FAAH and reduces 2 -AG hydrolysis by approximately $85 \%$, thereby elevating brain 2 -AG by 8 -fold, and for at least 8 hours after in vivo drug administration in mice (Long et al., 2009). JZL184 is effective in vivo and attenuates acute, mitogen-induced paw inflammation and neuropathy-induced neuropathic pain. Using a chronic constriction injury model, Kinsey et al. (2009) demonstrated that stimulus hypersensitivity resulting from chronic peripheral nerve injury is attenuated by JZL184 (16 mg/kg), an effect blocked by the $\mathrm{CB}_{1}$ receptor antagonist Rimonabant $(3 \mathrm{mg} / \mathrm{kg})$, but not the $\mathrm{CB}_{2}$ receptor antagonist SR144526 (3 mg/kg). Interestingly, the effects of $16 \mathrm{mg} / \mathrm{kg}$ JZL184 in mechanical and cold allodynia are absent in FAAH knockout mice, indicating that the observed analgesia is FAAH-independent (Kinsey et al., 2009). These data support the hypothesis that JZL184-induced analgesia is selectively mediated through MAGL inhibition.

Another MAGL inhibitor, KML29, reduces sensitivity to tactile and cold stimuli in mice receiving chronic constriction injury (Crowe et al., 2017). Moreover, additive or synergistic interactions are observed when low doses of KML29 and the antiepileptic drug gabapentin are administered in combination. These interactions are only partially mediated through $\mathrm{CB}_{1}$, and not mediated through $\mathrm{CB}_{2}$, suggesting that these drugs are acting through distinct mechanisms. No drug interaction side effects of immobility, catalepsy, or hypothermia were observed. This same drug synergism is seen in the chronic constriction injury model when mice receive combined 
treatment of low dose JZL184 and the non-steroidal anti-inflammatory drug diclofenac (Crowe et al., 2015).

JZL184 also attenuates chronic, chemotherapy-induced pain in mice. Administration of the chemotherapeutic agent cisplatin once a week for 3 weeks generates mechanical and cold hypersensitivities in Sprague-Dawley rats (Guindon et al., 2013). JZL184 blocks cisplatininduced hypersensitivity to an extent that is similar to morphine and with a higher maximal efficacy (Emax) than gabapentin (100 mg/kg) (Guindon et al., 2013). The effects of MAGL inhibition, via JZL184 or MJN110, are absent in mice treated with $\mathrm{CB}_{1}$ or $\mathrm{CB}_{2}$ selective antagonists or genetic deletion, but not deletion of TRPV1, a non-cannabinoid receptor that binds anandamide (Donvito et al., 2017). Thus, the analgesia induced by MAGL inhibition is mediated through both $\mathrm{CB}_{1}$ and $\mathrm{CB}_{2}$, (Curry et al., 2018). Similarly, mice administered paclitaxel show less neuropathic pain when administered JZL184 (Curry et al., 2018).

Because MAGL inhibition decreases chronic and inflammatory pain in various rodent models of neuropathic and inflammatory pain, it is plausible that JZL184 also decreases the negative outcomes of chronic autoimmune disease, such as inflammatory arthritis. The current study was designed to test the hypothesis that repeated administration of the MAGL inhibitor JZL184 inhibits the progression of CIA in mice. The corollary hypothesis is that any observed anti-inflammatory effects of MAGL inhibition occur through activation of the $\mathrm{CB}_{2}$ receptor. To test these hypotheses, mice were subjected to collagen-induced arthritis, and repeatedly administered JZL184 (8 or $40 \mathrm{mg} / \mathrm{kg}$ ) or vehicle. To determine a possible receptor mechanism, a separate group of mice was subjected to CIA and treated repeatedly with JZL184 (40 mg/kg) along with the selective $\mathrm{CB}_{2}$ antagonist SR144528. Paw swelling was assessed, along with 
behavioral tests of paw function. Novel behavioral models of arthritis-induced behavioral dysfunction and paw proinflammatory cytokines were quantified via ELISA.

\section{$\underline{\text { Methods }}$}

\section{Animals}

Male DBA/1J mice ( $=110$; Jackson Laboratories; Bar Harbor, ME) were randomly assigned to all treatment conditions. The DBA/1J strain is used in models of arthritis because of its increased expression of MHC class II molecules. Female DBA/1J mice were excluded because they show almost complete resistance to collagen-induced arthritis (Holmdahl et al., 1986). Mice were housed in the West Virginia University Life Sciences Building vivarium in polysulfone cages with ad libitum food and water. Mice were group housed with 3-5 per cage in an AAALAC accredited facility on a $12 \mathrm{~h}$ light/dark cycle maintained at $21 \pm 1^{\circ} \mathrm{C}$ and $50 \pm 5 \%$ humidity. The WVU Animal Care and Use Committee approved all experimental protocols prior to the start of the experiments.

\section{Drugs}

The MAGL inhibitor JZL184 was purchased from Cayman Chemical (Ann Arbor, MI). The selective $\mathrm{CB}_{2}$ receptor antagonist SR144528 (SR2) was generously provided by the NIDA Drug Supply Program (Bethesda, MD). All drugs were dissolved in a vehicle solution of 5\% ethanol, 5\% Kolliphor EL (Sigma-Aldrich, St. Louis, MO), and 90\% normal saline (Kinsey \& Cole, 2013). All solutions were warmed to room temperature and injected subcutaneously at a volume of $10 \mu \mathrm{L} / \mathrm{g}$ body mass. 


\section{Collagen Induced Arthritis (CIA)}

Mice were deeply anesthetized with isoflurane (Phoenix Pharmaceuticals, Burlingame, $\mathrm{CA}$ ), and $100 \mu \mathrm{l}$ of an emulsion of bovine type II collagen ( $2 \mathrm{mg} / \mathrm{ml})$ (Chondrex, Inc., Redmond, WA), dissolved in $0.05 \mathrm{M}$ acetic acid, in an equal volume of complete Freund's adjuvant (CFA) was injected intradermally, approximately $1 \mathrm{~cm}$ from the distal end of the tail. Twenty-one days later (Impellizzeri et al., 2013; Brand, Latham, \& Rosloniec, 2007), mice received a second "booster" exposure to the collagen emulsion, in an equal volume of incomplete Freund's adjuvant (IFA), injected midway between the tail base and first exposure site (Figure 1). Control mice received an emulsion of IFA and acetic acid without collagen for both injections. The CFA consisted of M. tuberculosis (4 mg/ml) (Becton, Dickinson and Company, Franklin Lakes, NJ) suspended into 85\% heavy mineral oil (O122-1, Fisher Scientific, Pittsburgh, PA) and 15\% mannide monooleate (AC332130250, Fisher Scientific, Pittsburgh, PA). The IFA was prepared identically to the CFA but did not contain M. tuberculosis.

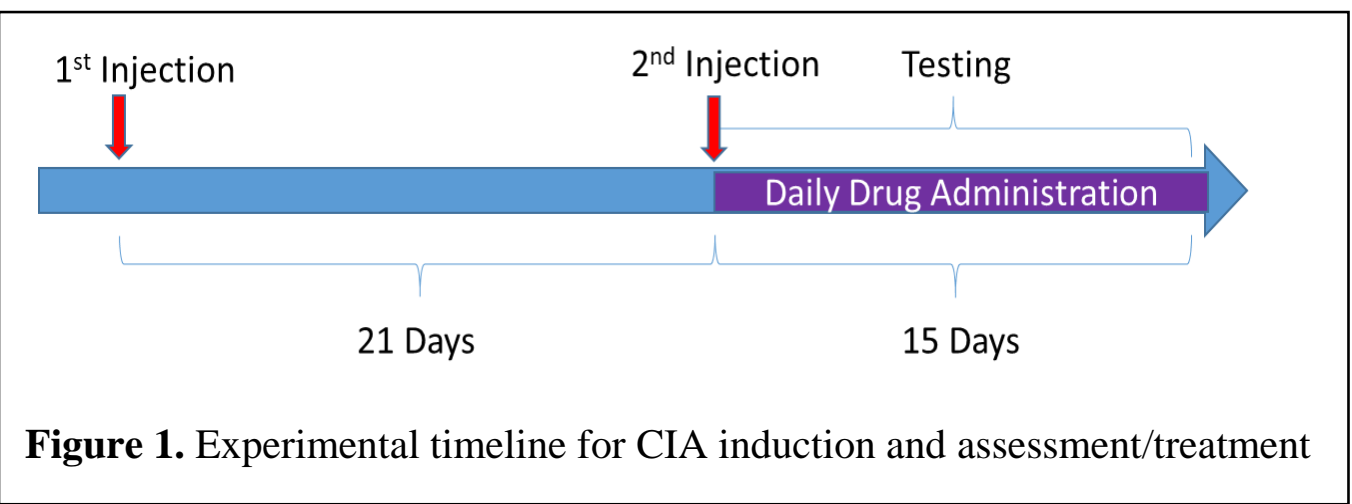




\section{Paw Thickness and Clinical Scoring}

Clinical Scores: Forepaws and hindpaws were examined using a clinical scoring system (Kinsey et al., 2011a) that quantified the magnitude of paw inflammation by assigning the numbers 0-4 to qualitative categories as follows: 0 , normal; 1 , erythema and mild swelling confined to the ankle joint or toes; 2, erythema and mild swelling extending from the ankle to the midfoot or ankle joint; 3, erythema and moderate swelling extending from the ankle to the metacarpal/metatarsal joints; 4, erythema and severe swelling encompassing the ankle, foot, and digits. The scores for each limb were summed for each mouse, resulting in a composite arthritis score with a maximum of 16 total points. Composite scores for hindpaws only were also calculated.

Paw Thickness: A digital micrometer (Wixey WR100) was used to measure hindpaw thickness to the nearest $0.01 \mathrm{~mm}$. The mean of the hindpaw measures for each mouse was used for analysis.

\section{Behavioral Assessments}

Balance Beam Test: The balance beam test is used to assess mouse motor performance and coordination (Luong, Carlisle, Southwell, \& Patterson, 2011). Mice were placed on the end of a 0.6 to $2.5 \mathrm{~cm}$ wide $100 \mathrm{~cm}$ long beam suspended $50 \mathrm{~cm}$ above the ground. Mice were given three trials to traverse an $80 \mathrm{~cm}$ length of the beam within a $60 \mathrm{~s}$ maximum trial time. A bright light was directed towards the starting platform, with a black escape box filled with food and nesting materials positioned at the other end of the apparatus. Performance during each trail was operationalized as latency to traverse the balance beam. Once a mouse moved all 4 of its paws past a line $15 \mathrm{~cm}$ from the starting end of the beam, a timer was activated. The timer was inactivated once all 4 paws had passed another line $80 \mathrm{~cm}$ past the starting line. Any mouse that took more than $60 \mathrm{~s}$ to traverse the starting line, or did not pass the starting line, was given a 
latency score of $60 \mathrm{~s}$ for that trial. In experiment $3,0 \%$ of mice in the control group, $55 \%$ of mice in the CIA group, 22\% of mice in the JZL184 group, and 55\% of mice in SR2 group were scored this way. Mice that did not move across the starting line within $10 \mathrm{~s}$ were prompted to move forward via a light touch by the experimenter.

Digging Test: Mice begin displacing fresh bedding as a function of being placed in a novel environment (Deacon, 2006). Individual mice were placed in a novel 30 x 40 x $16 \mathrm{~cm}$ plastic test chamber filled with $5 \mathrm{~cm}$ of wood bedding (090 A; Envigo, Indianapolis, IN). Mice were video recorded for 10 min and digging bout frequency and duration were hand coded by a blinded observer.

Grip Strength Test: Mice where placed on a metal cage top that was then gently inverted over a padded surface (Montilla-García et al., 2017; Deacon, 2013). Mice were then suspended upside down for a maximum of $60 \mathrm{~s}$. The dependent variable is latency to fall from the metal cage top. This task is used every other day and data are reported as the highest score each subject produces over 3 trials, each separated by 300 s.

Enzyme-Linked Immunosorbent Assay (ELISA)

After behavioral testing was complete, mice were euthanized by $\mathrm{CO} 2$ asphyxia, and hindpaws were collected and snap frozen in liquid nitrogen, then stored at $-80^{\circ} \mathrm{C}$ until assay. Samples were cut into small pieces with scissors and homogenized in $1.5 \mathrm{ml}$ phosphate-buffered saline, using a (Tissue Tearor, Bartlesville, OK). Samples were diluted 10-fold in PBS and assayed in duplicate, per manufacturer's protocol (R\&D Systems, Minneapolis, MN).

96-well plates were coated with an anti-mouse capture antibody (derived from goat or rat immune cells that were exposed to the target mouse protein) and incubated at room temperature 
overnight. The following day, the samples and standards were added to each plate and incubated at room temperature for $2 \mathrm{~h}$. Samples were decanted, and each plate was washed 3 times with wash buffer (0.05\% Tween 20 in PBS). A detection antibody was added to each well and incubated at room temperature for $2 \mathrm{~h}$. The cytokines become "sandwiched" between the capture antibody and detection antibody. Horseradish peroxidase (Streptavidin-HRP) was added to each well and incubated for $20 \mathrm{~min}$. HPR links the detection antibody to a chemical tag (i.e., a 1:1 mixture of $\mathrm{H}_{2} \mathrm{O}_{2}$ and Tetramethylbenzidine) that produces color. The color reaction was halted after 20 min incubation in the dark by $2 \mathrm{~N} \mathrm{H}_{2} \mathrm{SO}_{4}$. Optical densities were determined with a V max kinetic microplate reader (Molecular Devices, Sunnyvale, CA) and read at $450 \mathrm{~nm}$ with a $560 \mathrm{~nm}$ correction. Values for known standards on each plate were plotted. Optical density of each sample was fitted to a standard curve made of known concentrations of each cytokine, using polynomial regression. Data are reported as the mean of the duplicates.

\section{Statistical Analyses}

All data were analyzed using either one- or two-way mixed ANOVA followed by Bonferroni post hoc, with experimental treatment as a between subjects variable and days after booster injection as a within subject variable. Pearson's r correlation was used to determine direct relations between paw cytokine level and paw thickness. All data are represented as mean \pm S.E.M. Mean differences are considered statistically significant if $\mathrm{p}<0.05$. 


\section{$\underline{\text { Results }}$}

Experiment 1: Repeated MAGL inhibition (8 mg/kgJZL184) has no effect on CIA

On the morning of the booster injection (i.e, the second collagen exposure) mice were injected with JZL184 (8 mg/kg, sc) or vehicle, $2 \mathrm{~h}$ prior to the collagen injection. JZL184 was injected once daily for 15 days. Clinical scores and hindpaw thickness were assessed daily, and grip strength was assessed every two days. Digging was assessed on day 15 post-booster. All behavioral assays concluded prior to drug administration.

Interaction effects of drug treatment and time were found for clinical scores $[\mathrm{F}(30,375)=14.37$; $\mathrm{p}<0.05$; Figure 2A], paw thickness $[\mathrm{F}(28,350)=11.5 ; \mathrm{p}<0.05$; Figure 2B], and grip strength $[\mathrm{F}(14,175)=11.65 ; \mathrm{p}<0.05 ;$ Figure 2C $]$. Post hoc analyses revealed increases in arthritis for the CIA group relative to Control at about one week after booster injection. Clinical scores, paw thickness, and grip strength for the CIA group were also increased relative to baseline on days 8 , 9, and 9, respectively. JZL184 had no effect in any of the assays, with an exception of paw thickness on day 14 post-booster. Post hoc analyses revealed that clinical scores, paw thickness, and grip strength for the CIA + JZL184 group were increased relative to baseline starting on day 7 post-booster. CIA caused a statistically significant decrease in digging $[\mathrm{F}(2,25)=33.32 ; \mathrm{p}<$

0.05; Figure 2D], as measured on day 15 post-booster. Post hoc analyses revealed that JZL184 treatment had no effect on this CIA-depressed digging.

\section{Experiment 2: Repeated MAGL inhibition (40 mg/kg JZL184) attenuates CIA}

On the morning of the booster injection (i.e, the second collagen exposure) mice were injected with JZL184 (40 mg/kg, sc) or vehicle, $2 \mathrm{~h}$ prior to the collagen injection. An extra control group (no CIA) was injected with JZL184 to test for drug side effects. JZL184 was injected once daily for 15 days. Clinical scores and hindpaw thickness were assessed daily, and 
grip strength was assessed every two days. Balance beam performance was assessed on day 14 post-booster while digging was assessed on days 10 and 15 post-booster. All behavioral assays concluded prior to drug administration.

Interaction effects of drug treatment and time were found for clinical scores $[\mathrm{F}(45,510)$ $=9.551 ; \mathrm{p}<0.05$; Figure 3A $]$, paw thickness $[\mathrm{F}(42,476)=3.616 ; \mathrm{p}<0.05 ;$ Figure 3B $]$, and grip strength $[\mathrm{F}(21,238)=2.607 ; \mathrm{p}<0.05$; Figure $3 \mathrm{C}]$. Post hoc analyses revealed increases in arthritis for the CIA group relative to Control at about one week after booster injection. Clinical scores, paw thickness, and grip strength for the CIA group were also increased relative to baseline on days 8,7 , and 13 , respectively. Post hoc analyses comparing treatment groups revealed an attenuation of arthritis by JZL184 in clinical score, paw thickness, and grip strength tests, but post hoc analyses also revealed that clinical scores and paw thickness for the CIA + JZL184 group were increased relative to baseline starting on days 10 and 11 post-booster, respectively. CIA immunization or JZL184 administered alone caused a decrease in digging $[\mathrm{F}(3,33)=10.77 ; \mathrm{p}<0.0001 ;$ Figure 3D $]$, as measured on day 15 post-booster. Digging was also suppressed by CIA or JZL184 on day 10 post-booster $[\mathrm{F}(3,34)=12.5 ; \mathrm{p}<0.0001]$. CIA increased latency to traverse the balance beam, and JZL184 normalized this latency $[\mathrm{F}(1,34)=$ $4.548, \mathrm{p}<0.05 ;$ Figure 4].

Experiment 3: JZL184 attenuation of CIA is predominantly mediated through $\mathrm{CB}_{2}$

On the morning of the booster injection mice were injected with JZL184 (40 mg/kg, sc), vehicle, or combined JZL184 and SR144528 $2 \mathrm{~h}$ prior to the collagen injection. JZL184 was injected once daily for 15 days. Clinical scores and hindpaw thickness were assessed daily, and grip strength was assessed every two days. Balance beam performance was baselined prior to the 
first immunization and assessed day 14 post-booster while digging was assessed on day 15 postbooster. All behavioral assays concluded prior to drug administration. ELISAs for MPO, TNF- $\alpha$, IL-1 $\beta$, IL-6, IL-10, and IL-17 were run in duplicate. Spleens were harvested and weighed.

Interaction effects of drug treatment and time were found for clinical scores $[\mathrm{F}(45,495)=$ 4.079; $\mathrm{p}<0.05$; Figure 5A $]$, paw thickness $[\mathrm{F}(42,462)=3.227 ; \mathrm{p}<0.05$; Figure 5B $]$, and grip strength $[\mathrm{F}(21,231)=2.593 ; \mathrm{p}<0.05$; Figure 5C $]$. Post hoc analyses revealed increases in arthritis for the CIA group relative to Control at about one week after booster injection. Clinical scores, paw thickness, and grip strength for the CIA group were also increased relative to baseline on days 7, 9, and 7, respectively. Post hoc analyses revealed an attenuation of arthritis by JZL184 in clinical score, paw thickness, and grip strength tests, and SR144528 was found to block JZL184 mediated decreases in clinical scores and paw thickness while having no effect in grip strength. Post hoc analyses revealed that the CIA + JZL184 group was only different from baseline on day 14 post-booster in the paw thickness assay. The CIA + JZL184 + SR144528 group had increased clinical scores, paw thickness, and grip strength relative to baseline on days 12, 10, and 13, respectively. Analysis of clinical scores from only hindpaws revealed a more robust antagonism by $\mathrm{SR} 144528[\mathrm{~F}(45,495)=4.135 ; \mathrm{p}<0.0001$; data not shown $]$ compared to scores accounting for forepaw swelling. This increased antagonism mimicked the effects of SR144528 in the paw thickness assay, which scores paw swelling as change in mean hindpaw thickness. Only the group receiving SR144528 had decreased digging compared to control [F(3, $33)=3.564 ; \mathrm{p}<0.05 ;$ Figure 5D], as measured on day 15 post-booster. CIA increased latency to traverse the balance beam, which was again normalized by $\operatorname{JZL184}[\mathrm{F}(3,33)=4.424, \mathrm{p}<0.05$; Figure 6]. Post hoc analyses show that SR144528 blocked the effects of JZL184 in balance beam. Day 15 paw thickness and clinical scores correlated with grip strength and balance beam 
$(\mathrm{p}<0.001)$ regardless of whether fore- or hindpaws were exclusivly used for the analysis (data not shown).

After behavior testing was complete (i.e., day 16 post booster) hindpaws were harvested for biomarker quantification via ELISA. CIA increased levels of MPO $[\mathrm{F}(3,33)=9.66, \mathrm{p}<0.05$; Figure 7], which was not reversed by JZL184. TNF- $\alpha[\mathrm{F}(3,33)=1.584, \mathrm{p}=0.2118], \mathrm{IL}-1 \beta$ $[\mathrm{F}(3,33)=2.063 ; \mathrm{p}=0.1241], \mathrm{IL}-6[\mathrm{~F}(3,33)=1.827 ; \mathrm{p}=0.1614], \mathrm{IL}-10[\mathrm{~F}(3,33)=1.406 ; \mathrm{p}=$ 0.2584], and IL-17 $[\mathrm{F}(3,33)=1.242 ; \mathrm{p}=0.3104]$ were unaffected by CIA. Hindpaw thickness correlated with MPO $\left[\mathrm{F}(1,35)=113.6, \mathrm{R}^{2}=0.7645, \mathrm{p}<0.0001\right.$; Figure 8], IL-1 $\beta[\mathrm{F}(1,35)=$ 61.2; $\left.\mathrm{R}^{2}=0.6362 ; \mathrm{p}<0.0001\right]$ and IL-17 $\left[\mathrm{F}(1,35)=39.61 ; \mathrm{R}^{2}=0.5309 ; \mathrm{p}<0.0001\right)$. Spleens harvested from CIA-treated mice were visibly larger, and the mass of spleen in all groups receiving CIA was higher than non-CIA control mice $[\mathrm{F}(3,33)=29.94, \mathrm{p}<0.05$; Figure 10], although JZL184 had no effect on this splenomegaly. 


\section{$\underline{\text { Discussion }}$}

The goal of the present project was to determine the antiarthritic effects of MAGL inhibition in a model of collagen-induced arthritis (CIA). CIA caused paw swelling in mice about one week after booster injection. The MAGL inhibitor JZL184 attenuated signs of CIA. While a $8 \mathrm{mg} / \mathrm{kg}$ dose of JZL184 had no effect, $40 \mathrm{mg} / \mathrm{kg} \mathrm{JZL184}$ attenuated the development of clinical scores and paw swelling over 16 days of testing. Similarly, $40 \mathrm{mg} / \mathrm{kg}$ blocked the development of grip strength and balance beam deficits, but had no effects on CIA suppressed digging. $40 \mathrm{mg} / \mathrm{kg}$ JZL184 suppressed digging in mice independent of CIA immunization. These anti-arthritic effects of JZL184 replicated in a follow-up experiment that determined that $\mathrm{CB}_{2}$ receptors are necessary for most of the antiarthritic effects of JZL184. Hindpaw tissues levels of MPO increased as a function of CIA, an effect that was not blocked by $40 \mathrm{mg} / \mathrm{kg}$ JZL184. Surprisingly, CIA had no statistically significant effect on hindpaw proinflammatory cytokines.

\section{Endocannabinoid Catabolic Enzyme Inhibitors Attenuate CIA}

The efficacy of JZL184 in CIA-induced paw swelling (i.e., clinical scores and paw thickness) is similar to that of published data on the FAAH inhibitor URB597 to reduce clinical scores (Kinsey et al., 2011a). Genetic deletion of FAAH also reduces the incidence of CIA (Kinsey et al., 2011a). The resistance to CIA exhibited by FAAH knockout mice mediated through $\mathrm{CB}_{2}$, while the antinociceptive effects of URB597 are mediated though $\mathrm{CB}_{1}$ (Kinsey et al., 2011a). Despite the efficacy of FAAH inhibitors in rodent models of pain, clinical trials have, thus far, failed to demonstrate antinociceptive or anti-inflammatory efficacy (Singh, Kaur, \& Sidhu, 2016). 
MAGL inhibitors could be used in conjunction with FAAH inhibitors to increase therapeutic effects. Positive drug interactions occur between JZL184 and the selective FAAH inhibitor PF-3845 (Ghosh et al., 2015). Combined treatment enhances efficacy relative to JZL184 or PF-3845 treatment alone in both the chronic constriction model of neuropathic pain and the carrageenan model of inflammatory pain (Ghosh et al., 2015). While JZL184 and PF3845 reduce carrageenan-induced paw swelling, combined treatment does not increase drug efficacy (Ghosh et al., 2015). The effects of combined treatment on neuropathic and inflammatory pain is found to be $\mathrm{CB}_{1}$ mediated while the anti-edema effects of combined treatment are mediated through $\mathrm{CB}_{2}$ (Ghosh et al., 2015). While carrageenan administration produces acute inflammation, the effects of JZL184 in a chronic autoimmune disorder, such as CIA, has yet to be tested. Future experiments could test the effects of combined JZL184 and PF3845 in CIA.

\section{$\underline{\text { JZL184 Mechanisms of Action }}$}

The $\mathrm{CB}_{2}$ receptor antagonist SR144528 (3 mg/kg) blocked the effects of JZL184 (40 $\mathrm{mg} / \mathrm{kg}$ ) in clinical score, paw thickness, and balance beam tests, but had no effect in the grip strength test. One explanation for this inconsistency is that grip strength may be particularly sensitive to CIA effects because it is mediated by one or more non-canabinoid mechanism(s) of action. 2-AG upregulation, and subsequent $\mathrm{CB}_{1}$ and/or $\mathrm{CB}_{2}$ activation, is not the only mechanism of MAGL inhibition. Nomura et al. (2011) found an alternative anti-inflammatory pathway involving the degradation of 2-AG. Mice receiving intraperitoneal injections of the lymphocyte TLR4 receptor agonist lipopolysaccharide had brain cytokines quantified by ELISA after receiving JZL184 (40 mg/kg) or vehicle. JZL184 blocked lipopolysaccharide-induced increases in IL-1, IL-6, and TNF $\alpha$. These effects were barely attenuated by $\mathrm{CB}_{1}$ or $\mathrm{CB}_{2}$ antagonist 
pretreatment, suggesting a non-cannabinoid mechanism of action. Using mass spectrometry, brains extracted from mice missing MAGL were shown to express higher levels of 2-AG and lower levels of arachidonic acid than wild type controls. These effects can also be generated by pharmacologically inhibiting MAGL with JZL184. MAGL knockout mice produce reductions in pro-inflammatory prostanoids such as $\mathrm{PGE}_{2}$ and $\mathrm{PGD}_{2}$. These prostanoids are synthesized from arachidonic acid by cyclooxygenase enzymes. Possible mechanisms of action for JZL184 are depicted in Figure 9.

The decrease in arachidonic acid, a rate-limiting precursor for prostanoid synthesis, has anti-inflammatory effects in mice that are cannabinoid receptor independent (Nomura et al., 2011). JZL184 produces synergistic effects when coadministered with the COX inhibitor diclofinac in a mouse model of neuropathic pain (Crowe et al., 2015). These data suggest that combined JZL184/NSAID treatment may allow for attenuation of CIA at lower doses of JZL184, and with a more robust efficacy, paralleling the effects of low dose dexamethasone (0.0625-0.5 $\mathrm{mg} / \mathrm{kg}$ ), a glucocorticoid receptor agonist (Steele, Nass, \& Kinsey, in prep). An alternative explanation is that SR144528 blockade of $\mathrm{CB}_{2}$ is incomplete, thus allowing JZL184-induced increases in 2-AG to access the receptor because of differences in half-life. This idea is unlikely, because JZL184 significantly increases brain 2-AG for at least $8 \mathrm{~h}$ and inhibits MAGL hydrolysis for over $24 \mathrm{~h}$ (Long et al., 2009), and SR144528 occupies CB 2 for at least $18 \mathrm{~h}$ (Rinaldi-Carmona et al., 1998). Future studies may use genetic deletion of $\mathrm{CB}_{2}$ to test its necessity for the anti-inflammatory effects of MAGL in the CIA model. Such a knockout model offers advantages over antagonist administration, especially if an inducible model was used. But, currently available $\mathrm{CB}_{2}$ (-/-) would first need to be backcrossed onto a DBA/1 background strain for many generations, and is thus beyond the score of the present thesis project. 


\section{$\underline{\text { Effects of } \mathrm{CB}_{2} \text { agonists in CIA }}$}

Generally, the pattern of effects in the present study supports the idea that MAGL inhibition attenuates CIA via $\mathrm{CB}_{2}$. If this were the case, then it would be expected that direct $\mathrm{CB}_{2}$ agonism would also decrease CIA. Indeed, the selective $\mathrm{CB}_{2}$ agonist HU-308 attenuates CIAinduced increases in clinical scores and reduces hindpaw joint destruction, as determined by histology using hematoxylin-eosin staining (Gui et al., 2015). Similarly, the selective $\mathrm{CB}_{2}$ agonist JWH133 attenuates CIA- increased clinical scores and paw thickness and also decreased paw cartilage and paw bone destruction captured through $\mathrm{H} \& \mathrm{E}$ staining and microCT imaging, respectively (Zhu et al., 2018). CIA increased paw levels of IL-1, IL-6, and TNF $\alpha$ were also attenuated by JWH133 (Zhu et al., 2018). The effects of JWH133 in the CIA mouse model emulate the in vitro effects of JWH133 on synoviocytes isolated form the joint tissue of patients with $\mathrm{RA}$, which have increased $\mathrm{CB}_{2}$ expression relative to synoviocytes from patients who do not have RA (Fukuda et al., 2014). In these synoviocytes, TNF $\alpha$-stimulated IL-6 production is attenuated by JWH133, suggesting that $\mathrm{CB}_{2}$ agonists may exert anti-arthritic effects by decreasing proinflammatory cytokine production by synoviocytes.

$\mathrm{CB}_{2}$ activation is also associated with effector T cells that reduce autoimmunity (JeanGilles, Gran, \& Constantinescu, 2010). Selective $\mathrm{CB}_{2}$ agonist administration upregulates Treg cells and IL-10 levels using mouse splenocytes in a one-way mixed lymphocyte reaction assay (Robinson et al., 2015). Application of THC in mixed lymphocyte reaction assay reduced the ratio of pro-inflammatory Th1 cells to anti-inflammatory Th2 cells after allogeneic dendritic cell stimulation, thus attenuating macrophage signaling via the cytokine IFN- $\gamma$ (Yuan et al., 2002). This effect of THC was blocked by the selective $\mathrm{CB}_{2}$ antagonist SR144528 (Yuan et al., 2002). 
It is noteworthy that $\mathrm{CB}_{1}$ and $\mathrm{CB}_{2}$ cannabinoid receptor subtypes are expressed in both healthy and arthritic synovial joints (Richardson et al., 2008). Because both cannabinoid receptor subtypes are upregulated on lymphocytes within the synovial tissue of RA patients, it is plausible that combined activation of $\mathrm{CB}_{1}$ and $\mathrm{CB}_{2}$ receptors may facilitate greater antiarthritic efficacy than the selective activation of $\mathrm{CB}_{2}$ in clinical endpoints of nociception. However, given the well-established psychoactive effects of $\mathrm{CB}_{1}$ agonists, it would be advantageous to use a peripherally restricted $\mathrm{CB}_{1}$ agonist that would not cross the blood brain barrier. Future studies will use such an approach using a novel, peripherally restricted $\mathrm{CB}_{1}$ agonist.

\section{Assay Sensitivity and Behavioral Tolerance}

Differences in drug efficacy across assays demonstrates the importance of analyzing multiple morphological and functional symptoms of a disease state. For example, JZL184 (40 $\mathrm{mg} / \mathrm{kg}$ ) had no effect on CIA-depressed digging behavior. However, this same dose of JZL184 depresses marble burying (Kinsey et al., 2011b), a proxy measure of digging. Thus, the acute effects of JZL184 on digging may have masked the anti-inflammatory effects of JZL184. Indeed, digging was suppressed in the present study in control, non-CIA mice (Figure 3D). In contrast, JZL184 blocked CIA effects in the balance beam test. It may be that repeated JZL184 administration for 15 days induces tolerance, and that the digging test is more sensitive to the effects of MAGL inhibition that the balance beam test. Alternatively, the digging assay might be more sensitive to the side effects of repeated JZL184. Previous studies have demonstrated that 40 mg/kg JZL184 administered for 6 days can show behavioral tolerance (Schlosburg et al., 2010; Kinsey et al., 2013b), a phenomenon not observed in the digging assay of the present study. Again, this could reflect a difference in assay sensitivity to tolerance, but more notably, the mice in the current study were given JZL184 for almost 3 fold longer than in Schlosburg et al. (2010). 
This could mean that mechanisms downstream of behavioral tolerance are mitigating the effects of $40 \mathrm{mg} / \mathrm{kg} \mathrm{JZL184} \mathrm{in} \mathrm{digging,} \mathrm{possibly} \mathrm{due} \mathrm{to} \mathrm{neural} \mathrm{plasticity.}$

The digging test was used here as a pain-depressed behavior. Thus, had JZL184 treatment restored digging to non-CIA levels, it would indicate that pain was reduced while avoiding common locomotor confounds of extant analgesics, such as morphine. In future studies, the nestlet consolidation assay may be a useful alternative to digging. Nesting is the natural tendency of mice to consolidate or shred nestlets in their home cage (Gaskill et al., 2013). Nesting is sensitive to lactic acid-induced visceral pain, which results in less nestlet consolidation (Negus et al., 2015). Similar to the digging assay used in the current study, nesting assays can dissociate anti-nociceptive drug efficacy from generalized side effects. This prevents the confounding sedative effects of drugs from generating false positive antinocicpetive effects. One caveat of the nesting assays is that they require mice to be single housed for at least one week for mice to display robust nestlet consolidation over a $100 \mathrm{~min}$ (Negus et al., 2015). Given the relatively high sample size required to detect CIA effects, single housing 60+ mice is not a trivial exercise, and changing to such a model would require strong rationale. My own pilot data using mice subjected to chronic constriction injury revealed no effect of CCI on either nest building or digging (data not shown). But, the loss of function in the CIA model is of greater magnitude than that observed in the CCI model, so it is plausible that nesting would be suppressed by CIA.

\section{Effects of JZL184 on Inflammatory Mediators}

We hypothesized that CIA-induced increases in arthritic signs would correlate with increased paw levels of TNF- $\alpha$, IL-1 $\beta$, IL-6, IL-10, IL-17, or MPO. IL-6 mitigates how CD4+ T cells differentiate, and IL-6 is associated with greater T-helper 17 (Th17) to regulatory T (Treg) 
cell ratios in RA patients and mice with CIA (Thiolat et al., 2014). Excessive levels of IL-17 are found in the synovial joints of RA patients, and IL-17 is secreted from pro-inflammatory Th17 cells (Jin \& Dong, 2013). We found no statistically significant effects of CIA on paw cytokine or chemokine levels, although all samples assayed were within the detection limits of the ELISA assay. This may be a function of the relatively late time point in which the hindpaws were harvested. To reduce animal numbers and allow comparisons between behavior and biomarkers, mice were euthanized two weeks after the booster. It is plausible that cytokine differences would be more easily detected earlier in the development of overt signs of CIA (e.g., paw swelling). Mice receiving CIA show peak IL-1 $\beta$ and IL-6 levels at 1 to 4 days after the onset of arthritis, and these levels are greatly reduced after 15 days of arthritis (Rioja et al., 2004).

Proinflammatory cytokines correlated with paw thickness. CIA increased MPO levels, but JZL184 had no effect on CIA-induced MPO, which indicates that neutrophils are recruited to the inflamed paws, regardless of JZL184 treatment. Splenomegaly was also observed in CIA mice, supporting the argument that JZL184 treatment does not reduce CIA-induced splenocyte recruitment (Figure 10). Behavioral and biochemical assays may reflect greater sensitivity of behavioral correlates to detect changes in arthritis. Figure 11 outlines a model of MAGL inhibitor efficacy during CIA pathology. It is possible that MAGL inhibitors decrease signs of arthritis without producing global immunosuppression. Global immunosuppression can lead to reduced immune responding to dangerous non-self antigens. It is noteworthy that IL-1 $\beta$ levels are greater in CIA when compared to Control only $(\mathrm{t}(17)=2.267, \mathrm{p}<0.05)$. Future CIA studies may also look at JZL184 attenuation of Th1/Treg ratios in mouse paw samples using flow cytometry. 


\section{$\underline{\text { Alternative Models of Inflammatory Arthritis }}$}

It is worth noting that the CIA preparation does have some translational limitations. CIAinduced mice show progressively greater paw swelling throughout the progression of the disease. RA patients do not experience this linear progression, they experience "flare-ups" of periodic cycling of swelling and arthritic pain (Kahlenberg \& Fox, 2011; Lee, Nassikas, \& Clauw, 2011). Despite this difference, both RA and CIA disease states are driven by autoimmunity, resulting in cartilage and bone destruction at synovial joints. Effects of drugs on autoimmune based arthritis cannot be assessed in joint inflammation models using joint CFA injections alone (MontillaGarcía et al., 2017). There is also a mouse model of osteoarthritis (OA), which uses intraarticular injections of $1 \mathrm{mg} / \mathrm{kg}$ monosodium iodoacetate (MIA) to induce joint swelling (Lorenz \& Grässel, 2014). The MAGL inhibitor MJN110 shows antinociceptive efficacy in MIA OA (Burston et al., 2016). Mice administered MJN110 (5 mg/kg, i.p.) show both increased pain thresholds in von Frey and more symmetric weight-bearing compared to vehicle treated mice during OA (Burston et al., 2016). There is also a model of collagen antibody-induced arthritis (CAIA), which uses antibody transfer to induce passive immunity and generates arthritic signs in less than half the time it takes for arthritis to emerge in CIA (Khachgian, 2006). In CAIA, systemic administration of an arthrogen-CIA monoclonal antibody cocktail is administered 3 days before systemic administration of LPS (Khachgian, 2006). Like the CFA model, OA and CAIA models do not characterize autoimmune disease.

Future studies may explore the role of diacylglycerol lipase $\beta$ (DAGL $\beta$ ) blockade in the attenuating CIA. DAGL $\beta$ is one of the anabolic enzymes that is required for 2-AG synthesis in macrophages, and DAGL $\beta$ inhibition decreases the synthesis of 2-AG by DAGL $\beta$ in immune cells (Donvito et al., 2017; Hsu et al., 2012; Figure 9). The DAGL $\beta$ inhibitor KT109 attenuates 
stimulus hypersensitivity across multiple endpoints, including acute LPS-induced paw inflammation, chemotherapy-induced neuropathic pain, and chronic constriction injury (Wilkerson et al., 2016). Additionally, KT109 has no known $\mathrm{CB}_{1}$ agonist-like effects and does not induce open field immobility, catalepsy, antinociception, or hypothermia (Wilkerson et al., 2016).

\section{Nociception vs. Behavioral Functionality}

The behavioral assays tested in this study (i.e., digging, balance beam, and grip strength) assessed how CIA administration reduced behavior, rather than generating it. The rationale for using novel arthritic endpoints was two-fold. Pilot research found that robust CIA suppresses pain stimulated endpoints, such as von Frey, Hargreaves plantar stimulation, and hot plate tests, masking the detection of inflammatory pain. The current study used endpoints of motivational/performance deficits to circumvent this issue. The second reason for using assays of behavioral dysfunction was to better complement clinical research. As mentioned above, in the Introduction, performance impairments are often observed in patients experiencing joint inflammation (Sokka, Kankainen, \& Hannonen, 2000). Because the ultimate goal of the present preclinical research is to inform the development of therapeutic treatments for inflammatory arthritis, it is particularly important that pre-clinical endpoints match symptoms observed in clinical trials, as much as is possible across species.

\section{Clinical Effects of Cannabinoids}

Cannabis is used for many reasons, and because it is not an FDA-approved drug, cannabis cannot be prescribed by physicians, although they may recommend it for many different applications. Similarly, user self-report gives some insight into what purported medical 
uses are being sought by individual users. A recent clinical trial assessed the self-reported treatment efficacies of cannabis for 21 different disease states (Baren et al., 2018). Cannabis use was most frequently reported as a migraine self-medicating treatment, but other symptoms, including general pain, chronic pain, and arthritic pain where reported by patients. Interestingly, arthritic pain treatment efficacy was reported by $9.3 \%(n=188)$ of the patients (Baren et al., 2018). It is noteworthy that $41.2-59.5 \%$ of these patients also reported other pain medication use, including opioids, which indicates that they are experiencing inadequate analgesia, but also complicates interpretation of these data. Regardless, arthritis patients use cannabis, which aligns with the idea that the endocannabinoid system modulates arthritis.

\section{Conclusion}

The data from the present study are proof-of-concept that MAGL inhibition is a putative target for the treatment of inflammatory arthritis. Future studies should test the efficacy of MAGL inhibition as an adjunctive treatment with current and future anti-arthritic or analgesic pharmacotherapies. For example, the synthetic glucocorticoid agonist dexamethasone produces robust anti-inflammation in the CIA model (Steele, Nass, \& Kinsey, in prep), suggesting that interactions may occur when glucocorticoid agonists and MAGL inhibitors are coadministered. These studies would aim to increase the potency of therapeutic drugs while not altering (or decreasing) the potency of drug treatment to produce side effects. Antiarthritic efficacy of dexamethasone to reduce deficits in behavioral assays could also be assessed in future studies. 

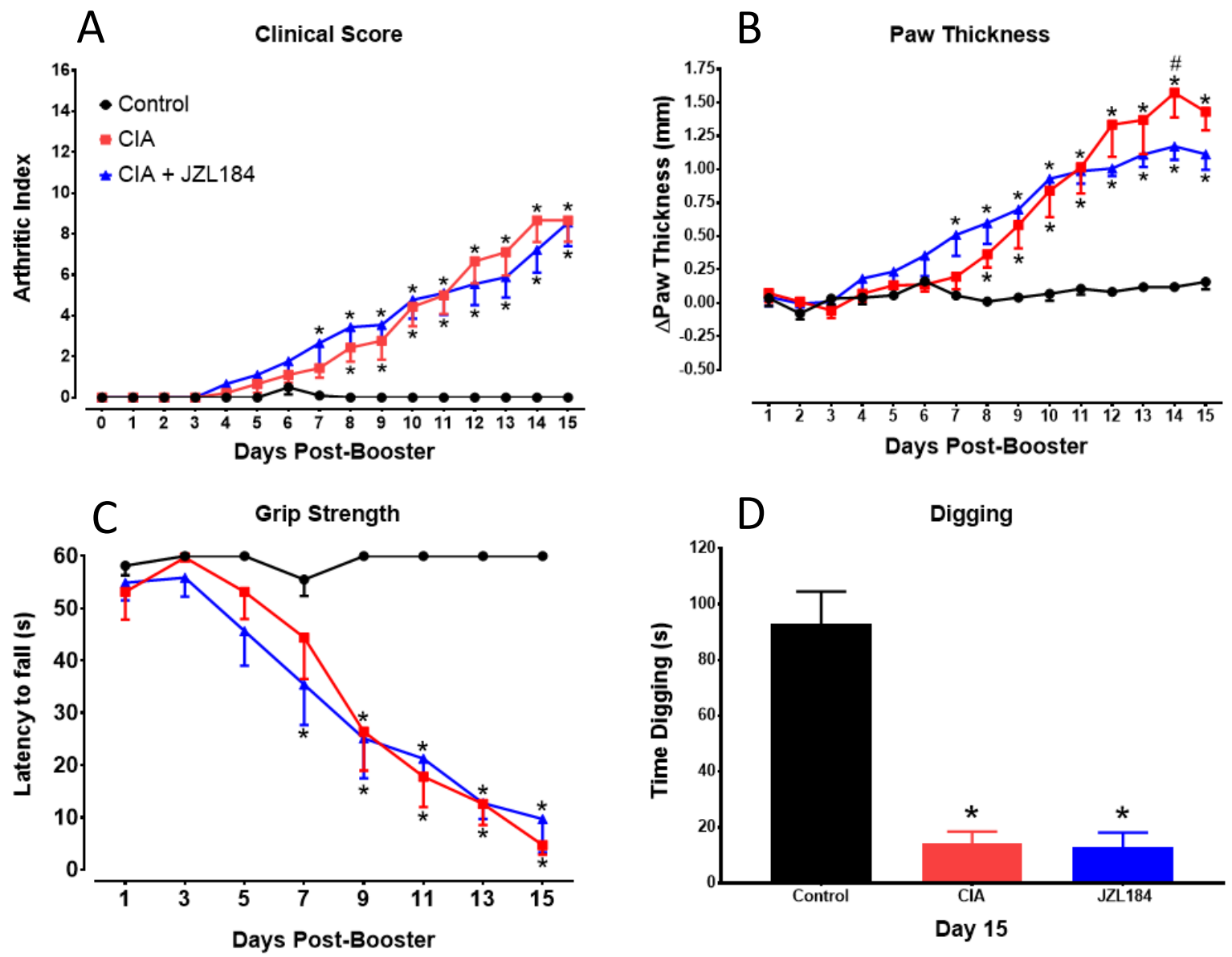

Figure 2. Repeated JZL184 (8 mg/kg, sc) has no effect on CIA induced paw swelling or behavior. $(\mathrm{A}, \mathrm{B})$ the hindpaws of mice subjected to CIA were measured daily following the secondary "booster" exposure to collagen. CIA depressed (C) grip strength in wire grid test, and (D) time digging in novel bedding. * $\mathrm{p}<0.05$ vs. Control. \# $\mathrm{p}<0.05$ vs. CIA + JZL184. ( $\mathrm{n}=9$ 10 males). 

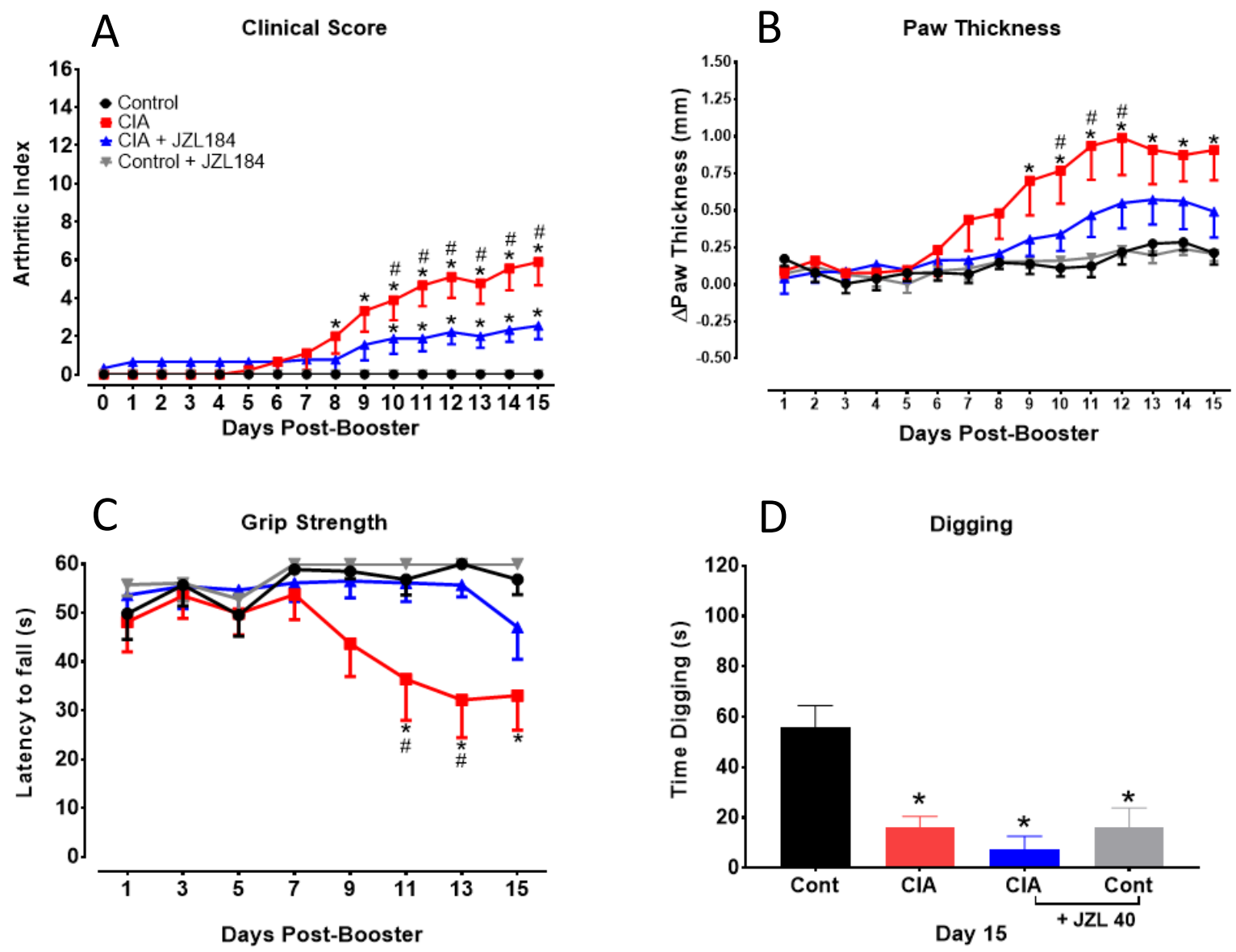

Figure 3. Repeated JZL184 (40 mg/kg, sc) attenuates CIA induced paw swelling and grip strength, but had no effect on digging. (A,B) the hindpaws of mice subjected to CIA were measured daily following the secondary "booster" exposure to collagen. CIA depressed (C) grip strength in wire grid test, and (D) time digging in novel bedding. * $\mathrm{p}<0.05$ vs. Control. \# $\mathrm{p}<$ 0.05 vs. CIA + JZL184. ( $\mathrm{n}=9-10$ males $)$. 


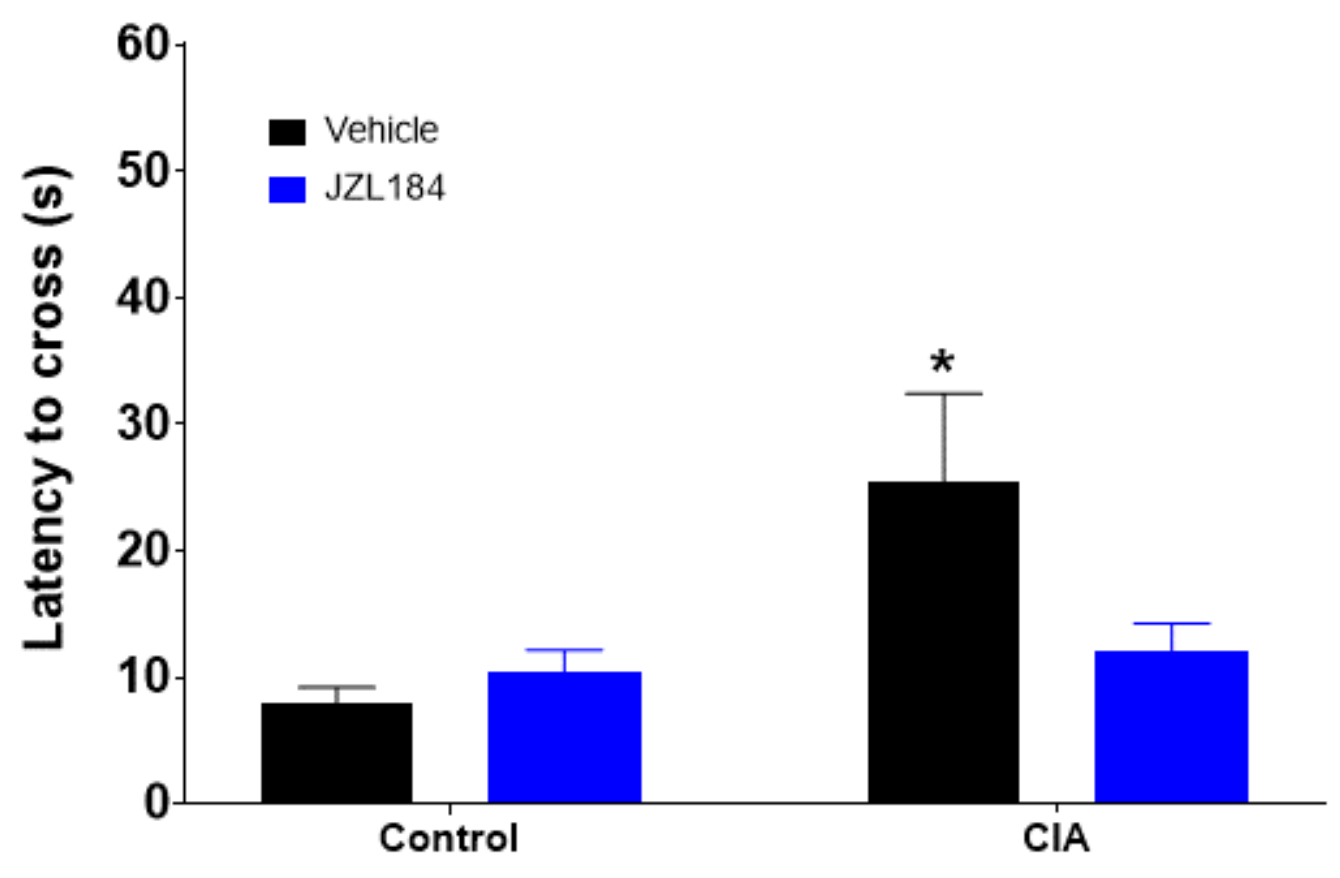

Day 14

Figure 4. Repeated JZL184 (40 mg/kg, sc) attenuates CIA induced deficits in latency to cross the balance beam. JZL184 had no effect in Control mice. * $\mathrm{p}<0.05$ vs. Vehicle Control. $(\mathrm{n}=9$ 10 males). 

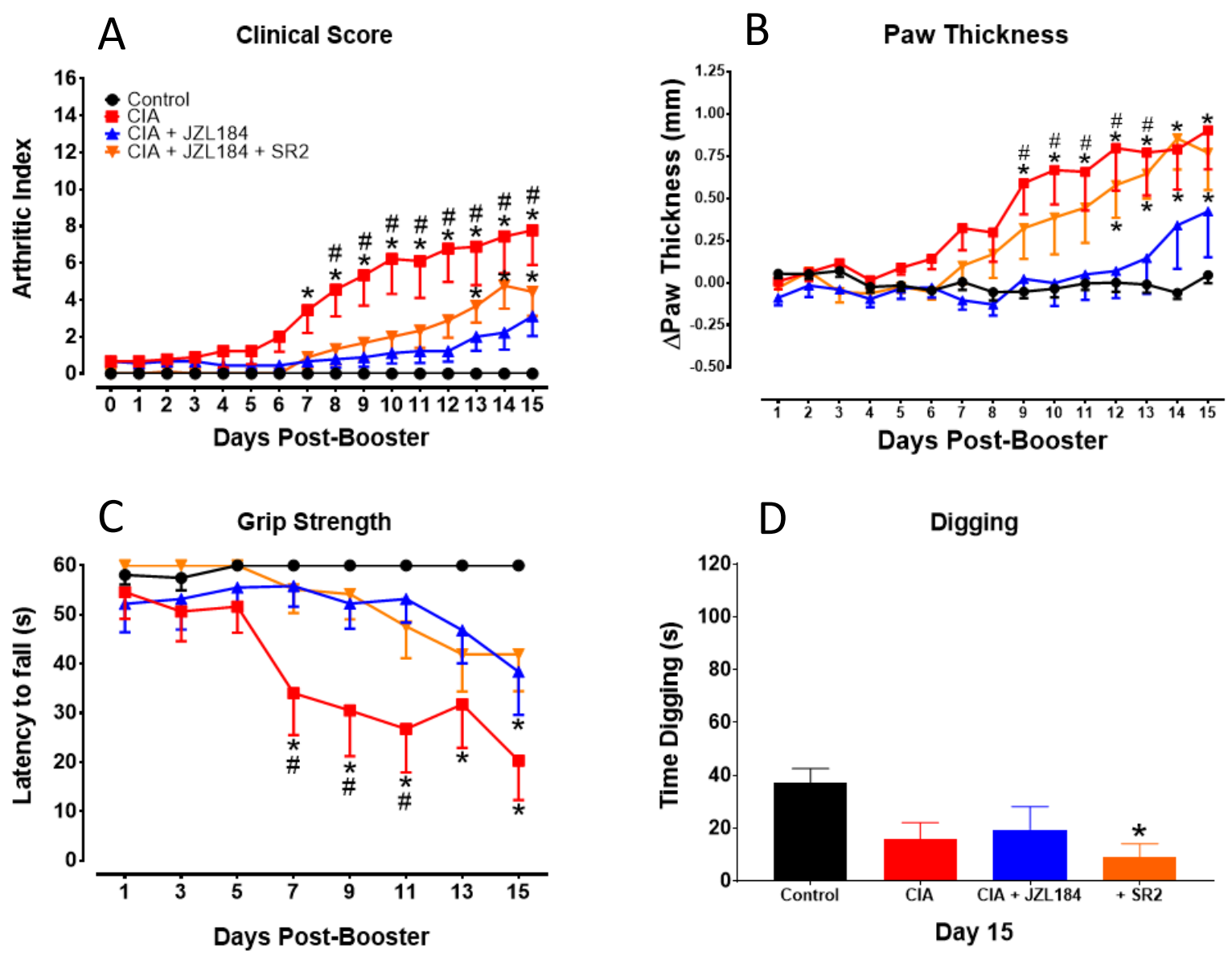

Figure 5. Repeated SR2 (3 mg/kg, sc) blocks the anti-arthritic effects of repeated JZL184 (40 $\mathrm{mg} / \mathrm{kg}, \mathrm{sc})$ in an assay-dependent manner. $(\mathrm{A}, \mathrm{B})$ the hindpaws of mice subjected to CIA were measured daily following the secondary "booster" exposure to collagen. CIA depressed (C) grip strength in wire grid test, and (D) time digging in novel bedding. * $\mathrm{p}<0.05$ vs. Control. \# $\mathrm{p}<$ 0.05 vs. CIA + JZL184. + p $<0.05$ for CIA + JZL184 + SR2 vs. Control. ( $n=9-10$ males). 


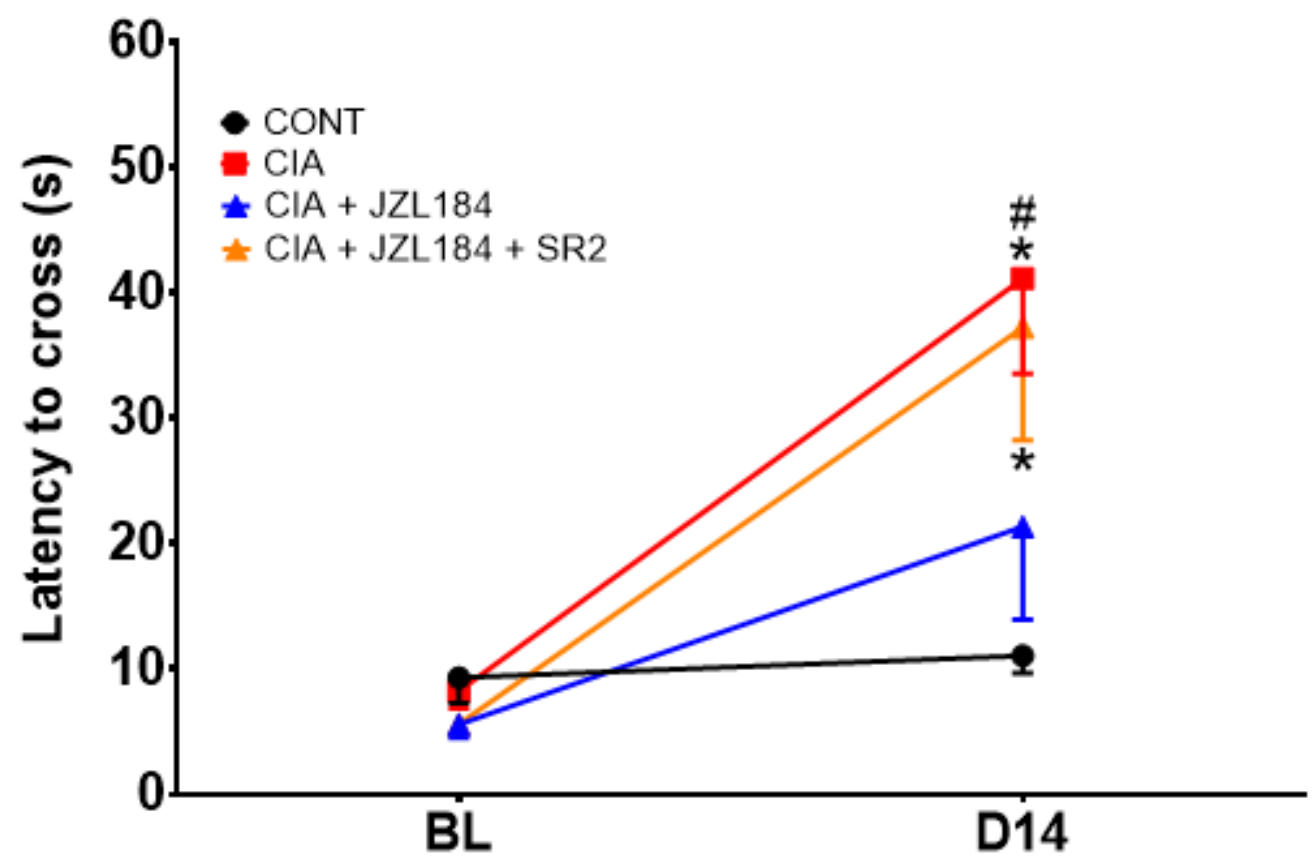

Figure 6. Repeated SR2 (SR144528; $3 \mathrm{mg} / \mathrm{kg}$, sc) blocks the anti-arthritic effects of JZL184 (40 $\mathrm{mg} / \mathrm{kg}, \mathrm{sc})$ in the balance beam test. $* \mathrm{p}<0.05$ vs. Control. $\# \mathrm{p}<0.05$ vs. CIA + JZL184. + $\mathrm{p}<$ 0.05 for CIA + JZL184 + SR2 vs. Control. $(\mathrm{n}=9-10$ males $)$. 

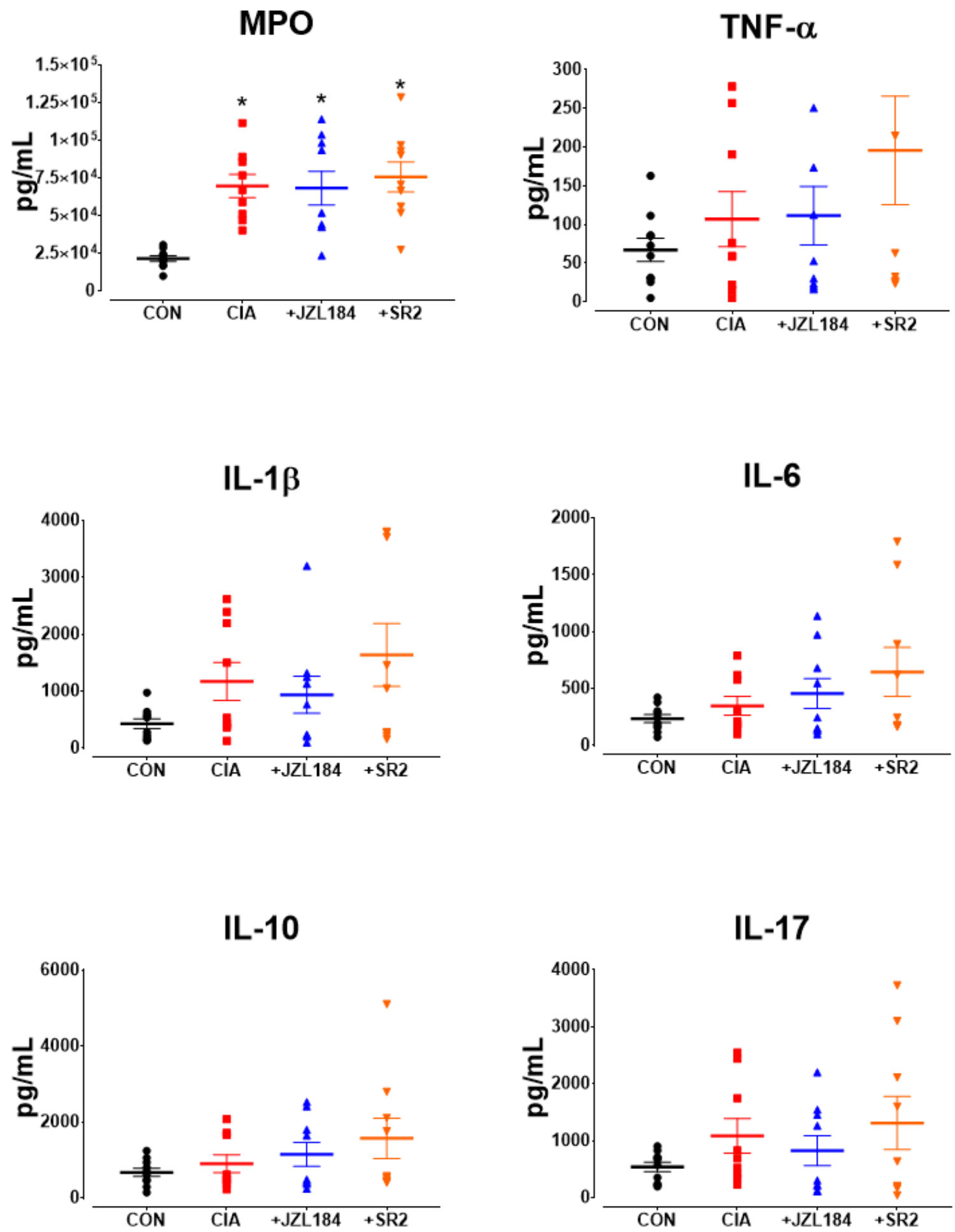

Figure 7. CIA increased myeloperoxidase but had no effect on TNF- $\alpha$, IL-1 $\beta$, IL-6, IL-10, or IL17 levels in whole paws. $* \mathrm{p}<0.05$ vs. Control. ( $\mathrm{n}=9-10$ males $)$. 

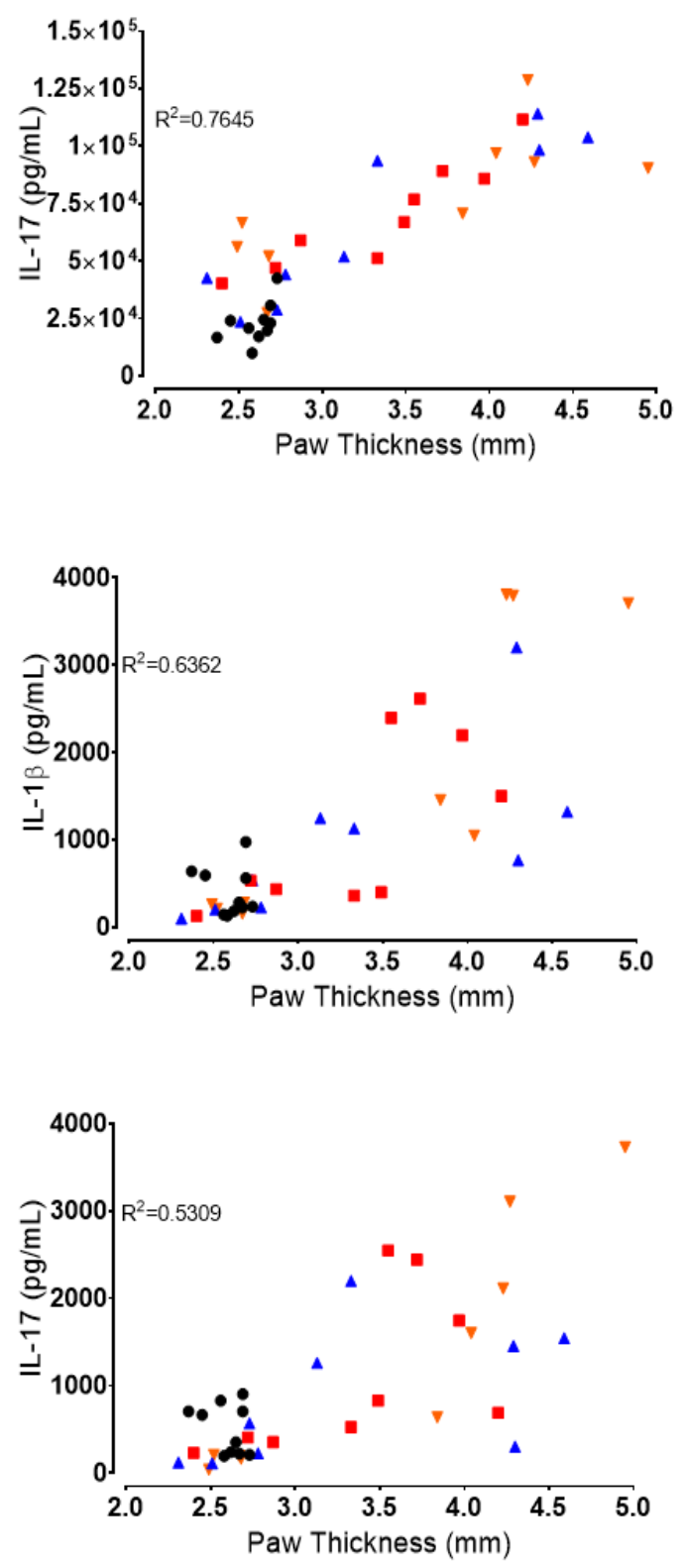

Figure 8. IL-1 $\beta$ (left) and IL-17 (right) paw cytokine concentrations are positively correlated with paw thickness. $\mathrm{r}$ is significant at $\mathrm{p}<0.0001$. Black circle $=\mathrm{CON}$, Red square $=\mathrm{CIA}$, Blue upward triangle $=$ CIA + JZL184, and Orange downward triangle $=$ CIA + JZL184 + SR144528 


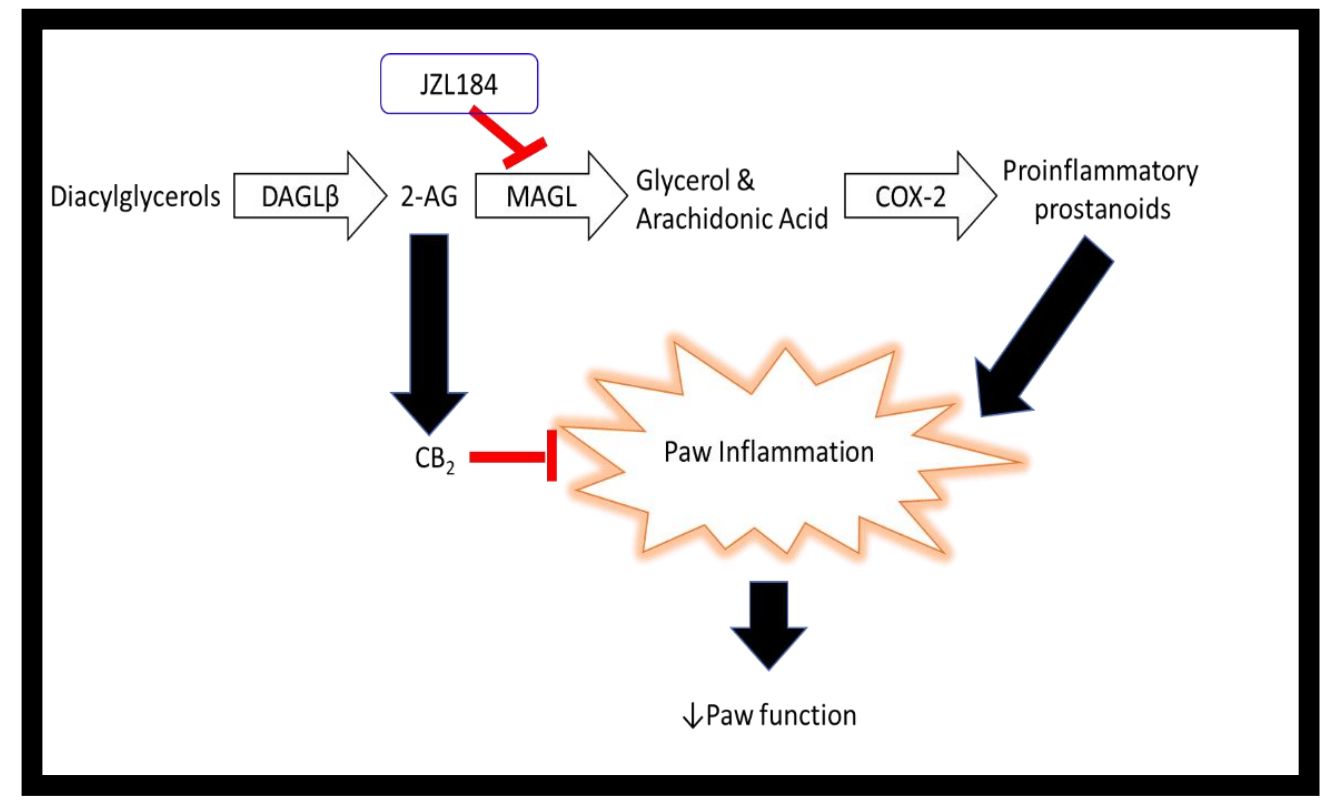

Figure 9. Mechanisms of JZL184 anti-inflammation. 2-AG synthesized by DAGL $\alpha / \beta$ from diacylglycerol is hydrolyzed by MAGL into glycerol and arachidonic acid. JZL184 blocks the degradation of 2-AG into arachidonic acid, resulting in increasesd 2-AG, which increases activation of $\mathrm{CB}_{2}$ receptors on immune cells, thereby reducing paw inflammation and resulting loss of function. In a parallel, cannabinoid receptor-independent mechanism, by preventing 2-AG hydrolysis, JZL184 starves arachidonic acid, a critical substrate for cyclooxygenase-2 (COX-2) in prostanoids synthesis. 


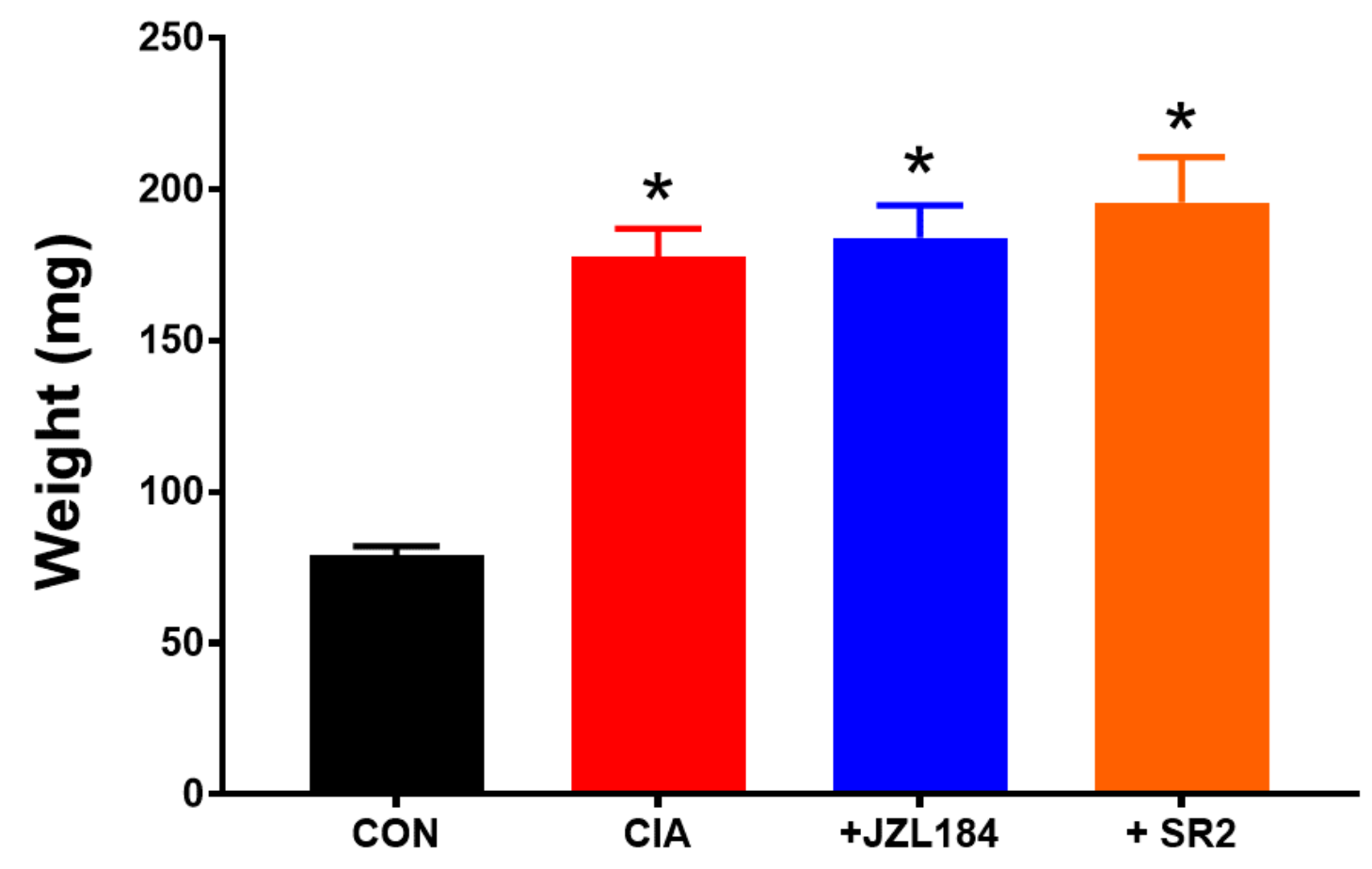

Figure 10. CIA induces splenomegaly. Spleens of mice in Experiment 3 were harvested on day 16 post-booster. ${ }^{*} \mathrm{p}<0.05$ vs. Control. $(\mathrm{n}=9-10)$. 


\section{CIA autoimmunity}

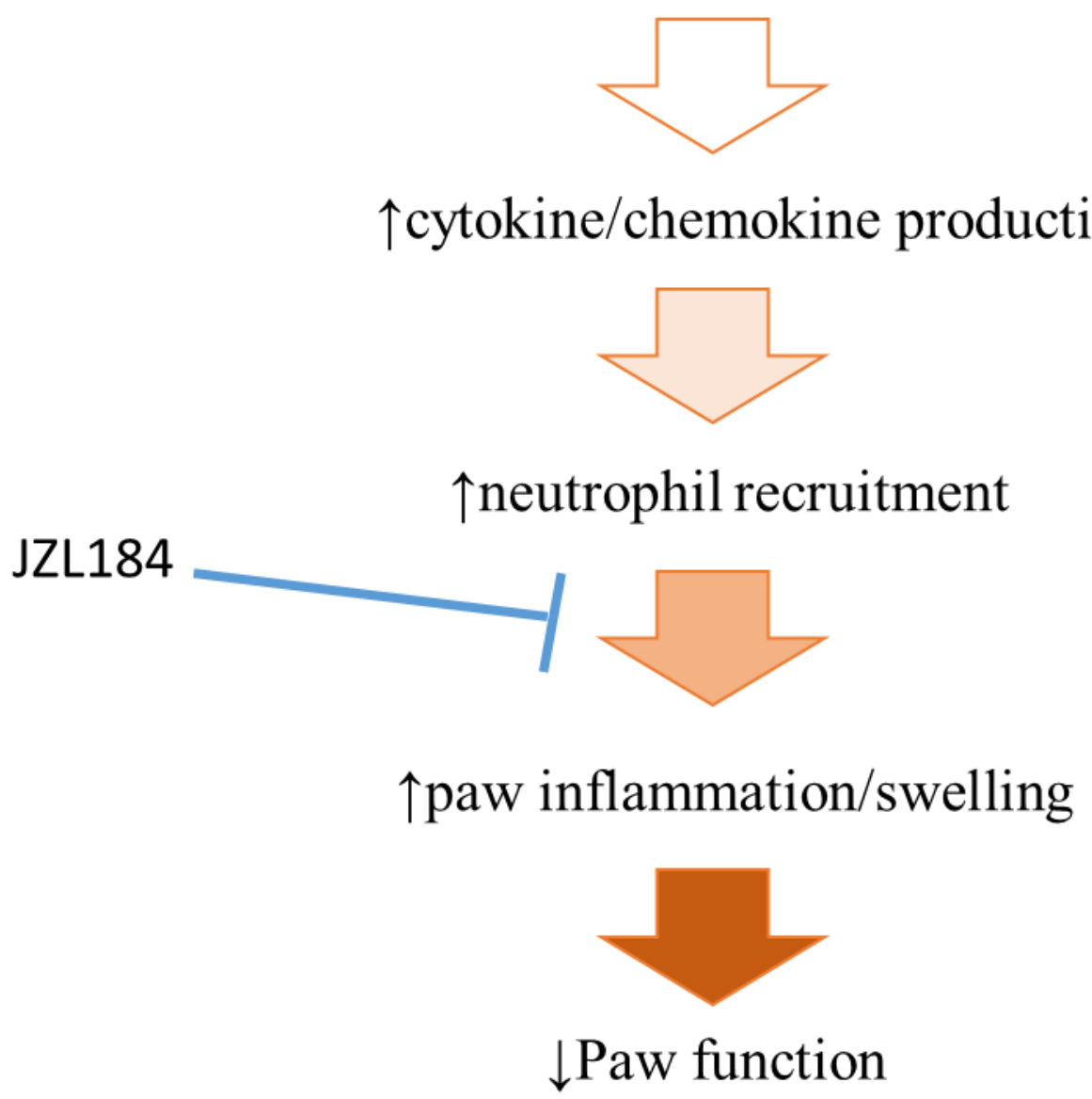

Figure 11. MAGL inhibition by JZL184 reduces inflammatory arthritis, without producing global immunosuppression. 


\section{References}

Blankman, J., Simon, G., \& Cravatt, B. (2007). A comprehensive profile of brain enzymes that hydrolyze the endocannabinoid 2-arachidonoylglycerol. Chemical Biology, 14(12), 13471356. doi: 10.1016/j.chembiol.2007.11.006

Baron, E. P., Lucas, P., Eades, J., \& Hogue, O. (2018). Patterns of medicinal cannabis use, strain analysis, and substitution effect among patients with migraine, headache, arthritis, and chronic pain in a medicinal cannabis cohort. The Journal of Headache and Pain, 19(1). doi:10.1186/s10194-018-0862-2

Booker, L., Kinsey, S. G., Abdullah, R. A., Blankman, J. L., Long, J. Z., Ezzili, C., Boger, D., Cravatt, B., \& Lichtman, A. H. (2012). The fatty acid amide hydrolase (FAAH) inhibitor PF-3845 acts in the nervous system to reverse LPS-induced tactile allodynia in mice. British Journal of Pharmacology, 165(8), 2485-2496. doi:10.1111/j.14765381.2011.01445.x

Brand, D. D., Latham, K. A., \& Rosloniec, E. F. (2007). Collagen-induced arthritis. Nature Protocols, 2(5), 1269-1275. doi:10.1038/nprot.2007.173

Burston, J. J., Mapp, P. I., Sarmad, S., Barrett, D. A., Niphakis, M. J., Cravatt, B. F., Walsh, D. A., \& Chapman, V. (2016). Robust anti-nociceptive effects of monoacylglycerol lipase inhibition in a model of osteoarthritis pain. British Journal of Pharmacology, 173(21), 3134-3144. doi:10.1111/bph.13574

Coutinho, A. E., \& Chapman, K. E. (2011). The anti-inflammatory and immunosuppressive effects of glucocorticoids, recent developments and mechanistic insights. Molecular and Cellular Endocrinology, 335(1), 2-13. doi:10.1016/j.mce.2010.04.005 
Crowe, M. S., Leishman, E., Banks, M. L., Gujjar, R., Mahadevan, A., Bradshaw, H. B., \& Kinsey, S. G. (2015). Combined inhibition of monoacylglycerol lipase and cyclooxygenases synergistically reduces neuropathic pain in mice. British Journal of Pharmacology, 172(7), 1700-1712. doi:10.1111/bph.13012

Curry, Z. A., Wilkerson, J. L., Bagdas, D., Kyte, S. L., Patel, N., Donvito, G., Mustafa, M. A. Poklis, J. L., Niphakis, M. J., Hsu, K. L., Cravatt, B. F., Gewirtz, D. A., Damaj, M. I., \& Lichtman, A. H. (2018). Monoacylglycerol Lipase Inhibitors Reverse Paclitaxel-Induced Nociceptive Behavior and Proinflammatory Markers in a Mouse Model of Chemotherapy-Induced Neuropathy. Journal of Pharmacology and Experimental Therapeutics, 366(1), 169-183. doi:10.1124/jpet.117.245704

Deacon, R. M. (2013). Measuring the Strength of Mice. Journal of Visualized Experiments, (76). doi: $10.3791 / 2610$

Donvito, G., Nass, S. R., Wilkerson, J. L., Curry, Z. A., Schurman, L. D., Kinsey, S. G., \& Lichtman, A. H. (2017). The Endogenous Cannabinoid System: A Budding Source of Targets for Treating Inflammatory and Neuropathic Pain. Neuropsychopharmacology. doi:10.1038/npp.2017.204

Fukuda, S., Kohsaka, H., Takayasu, A., Yokoyama, W., Miyabe, C., Miyabe, Y., Harigai, M., Miyasaka, N., \& Nanki, T. (2014). Cannabinoid receptor 2 as a potential therapeutic target in rheumatoid arthritis. BMC Musculoskeletal Disorders, 15(1). doi:10.1186/1471$2474-15-275$

Gaffo, A., Saaq, K. G., \& Curtis, J. R. (2006). Treatment of rheumatoid arthritis. American Journal of Health System Pharmacy, 63(24), 2451-2465. doi:10.2146/ajhp050514 
Gaskill, B. N., Karas, A. Z., Garner, J. P., \& Pritchett-Corning, K. R. (2013). Nest building as an indicator of health and welfare in laboratory mice. Journal of Visualized Experiments, $(82): 51012$

Ghosh, S., Kinsey, S. G., Liu, Q., Hruba, L., Mcmahon, L. R., Grim, T. W., Merritt, C. R., Wise, L. E., Abdullah, R. A., Selley, D. E., Sim-Selley, L. J., Cravatt, B. F., \& Lichtman, A. H. (2015). Full Fatty Acid Amide Hydrolase Inhibition Combined with Partial Monoacylglycerol Lipase Inhibition: Augmented and Sustained Antinociceptive Effects with Reduced Cannabimimetic Side Effects in Mice. Journal of Pharmacology and Experimental Therapeutics, 354(2), 111-120. doi:10.1124/jpet.115.222851

Grim, T. W., Ghosh, S., Hsu, K., Cravatt, B. F., Kinsey, S. G., \& Lichtman, A. H. (2014). Combined inhibition of FAAH and COX produces enhanced anti-allodynic effects in mouse neuropathic and inflammatory pain models. Pharmacology Biochemistry and Behavior, 124, 405-411. doi:10.1016/j.pbb.2014.07.008

Gui, H., Liu, X., Liu, L., Su, D., \& Dai, S. (2015). Activation of cannabinoid receptor 2 attenuates synovitis and joint distruction in collagen-induced arthritis. Immunobiology, 220(6), 817-822. doi:10.1016/j.imbio.2014.12.012

Gui, H., Liu, X., Wang, Z., He, D., Su, D., \& Dai, S. (2014). Expression of cannabinoid receptor 2 and its inhibitory effects on synovial fibroblasts in rheumatoid arthritis. Rheumatology, 53(5), 802-809. doi:10.1093/rheumatology/ket447

Guindon, J., Lai, Y., Takacs, S. M., Bradshaw, H. B., \& Hohmann, A. G. (2013). Alterations in endocannabinoid tone following chemotherapy-induced peripheral neuropathy: Effects of endocannabinoid deactivation inhibitors targeting fatty-acid amide hydrolase and 
monoacylglycerol lipase in comparison to reference analgesics following cisplatin treatment. Pharmacological Research, 67(1), 94-109. doi:10.1016/j.phrs.2012.10.013

Holmdahl, R., Jansson, L., Larsson, E., Rubin, K., \& Klareskog, L. (1986). Homologous type II collagen induces chronic and progressive arthritis in mice. Arthritis \& Rheumatism, 29(1), 106-113. doi:10.1002/art.1780290114

Hsu, K., Tsuboi K., Adibekian, A., Pugh, H., Masuda, K., \& Cravatt, B. (2012). DAGL $\beta$ inhibition perturbs a lipid network involved in macrophage inflammatory responses. Nat Chem Biol, 8, 999-1007.

Impellizzeri, D., Esposito, E., Paola, R. D., Ahmad, A., Campolo, M., Peli, A., Morittu, V. M., Britti, D., \& Cuzzocrea, S. (2013). Palmitoylethanolamide and luteolin ameliorate development of arthritis caused by injection of collagen type II in mice. Arthritis Research \& Therapy, 15(6). doi:10.1186/ar4382

Jean-Gilles, L., Gran, B., \& Constantinescu, C. S. (2010). Interaction between cytokines, cannabinoids and the nervous system. Immunobiology, 215(8), 606-610. doi:10.1016/j.imbio.2009.12.006

Jin, W., \& Dong, C. (2013). IL-17 cytokines in immunity and inflammation. Emerging Microbes \& Infections, 2(9). doi:10.1038/emi.2013.58

Kahlenberg, J. M., \& Fox, D. A. (2011). Advances in the medical treatment of rheumatoid arthritis. Hand Clinics, 27(1), 11-20. doi: 10.1016/j.hcl.2010.09.002

Khachigian, L. M. (2006). Collagen antibody-induced arthritis. Nature Protocols, 1(5):2512-6. 
Kinne, R. W., Bräuer, R., Stuhlmüller, B., Palombo-Kinne, E., \& Burmester, G. (2000). Macrophages in rheumatoid arthritis. Arthritis Research, 2(3), 189. doi:10.1186/ar86

Kinsey, S. G., \& Cole, E. C. (2013). Acute $\Delta$ 9-tetrahydrocannabinol blocks gastric hemorrhages induced by the nonsteroidal anti-inflammatory drug diclofenac sodium in mice. European Journal of Pharmacology, 715(1-3), 111-116. doi:10.1016/j.ejphar.2013.06.001

Kinsey, S. G., Long, J. Z., Oneal, S. T., Abdullah, R. A., Poklis, J. L., Boger, D. L., Cravatt, B. F., \& Lichtman, A. H. (2009). Blockade of endocannabinoid-degrading enzymes attenuates neuropathic pain. Journal of Pharmacology and Experimental Therapeutics, 330(3), 902-910. doi:10.1124/jpet.109.155465

Kinsey, S. G., Naidu, P. S., Cravatt, B. F., Dudley, D. T., \& Lichtman, A. H. (2011a). Fatty acid amide hydrolase blockade attenuates the development of collagen-induced arthritis and related thermal hyperalgesia in mice. Pharmacology Biochemistry and Behavior, 99(4), 718-725. doi:10.1016/j.pbb.2011.06.022

Kinsey, S. G., Oneal, S. T., Long, J. Z., Cravatt, B. F., \& Lichtman, A. H. (2011b). Inhibition of endocannabinoid catabolic enzymes elicits anxiolytic-like effects in the marble burying assay. Pharmacology Biochemistry and Behavior, 98(1), 21-27. doi:10.1016/j.pbb.2010.12.002

Kinsey, S. G., Wise, L. E., Ramesh, D., Abdullah, R., Selley, D. E., Cravatt, B. F., \& Lichtman, A. H. (2013). Repeated Low-Dose Administration of the Monoacylglycerol Lipase Inhibitor JZL184 Retains Cannabinoid Receptor Type 1-Mediated Antinociceptive and Gastroprotective Effects. Journal of Pharmacology and Experimental Therapeutics, 345(3), 492-501. doi:10.1124/jpet.112.201426 
Lee, Y. C., Nassikas, N. J., \& Clauw, D. J. (2011). The role of the central nervous system in the generation and maintenance of chronic pain in rheumatoid arthritis, osteoarthritis and fibromyalgia. Arthritis Research \& Therapy, 13(2), 211. doi:10.1186/ar3306

Lee, Y. C. (2013). Effect and Treatment of Chronic Pain in Inflammatory Arthritis. Current Rheumatology Reports, 15(1). doi:10.1007/s11926-012-0300-4

Long, J. Z., Li, W., Booker, L., Burston, J. J., Kinsey, S. G., Schlosburg, J. E., Pavon, F. J., Serrano, A. M., Selley, D. E., Parsons, L. H., Lichtman, A. H., \& Cravatt, B. F. (2009). Selective blockade of 2-arachidonoylglycerol hydrolysis produces cannabinoid behavioral effects. Nature Chemical Biology, 5(1), 37-44. doi:10.1038/nchembio.129

Lorenz, J., \& Grässel, S. (2014). Experimental Osteoarthritis Models in Mice. Methods in Molecular Biology Mouse Genetics, 401-419. doi:10.1007/978-1-4939-1215-5_23

Luong, T. N., Carlisle, H. J., Southwell, A., \& Patterson, P. H. (2011). Assessment of Motor Balance and Coordination in Mice using the Balance Beam. Journal of Visualized Experiments, (49). doi:10.3791/2376

Mcpartland, J. M., Glass, M., \& Pertwee, R. G. (2009). Meta-analysis of cannabinoid ligand binding affinity and receptor distribution: Interspecies differences. British Journal of Pharmacology, 152(5), 583-593. doi:10.1038/sj.bjp.0707399

Mechoulam, R., \& Parker, L. A. (2013). The endocannabinoid system and the brain. Annual Reviews of Psychology, 64, 21-47. doi:10.1146/annurev-psych-113011-143739

Montilla-García, Á, Tejada, M. Á, Perazzoli, G., Entrena, J. M., Portillo-Salido, E., FernándezSegura, E., Canizares, F. J., \& Cobos, E. J. (2017). Grip strength in mice with joint 
inflammation: A rheumatology function test sensitive to pain and analgesia. Neuropharmacology, 125, 231-242. doi:10.1016/j.neuropharm.2017.07.029

Moreira, F. A., Grieb, M., \& Lutz, B. (2009). Central side-effects of therapies based on CB1 cannabinoid receptor agonists and antagonists: focus on anxiety and depression. Best Practice \& Research Clinical Endocrinology \& Metabolism, 23(1), 133-144. doi:10.1016/j.beem.2008.09.003

Negus, S. S., Neddenriep, B., Altarifi, A. A., Carroll, F. I., Leitl, M. D., \& Miller, L. L. (2015). Effects of ketoprofen, morphine, and kappa opioids on pain-related depression of nesting in mice. Pain, 1. doi:10.1097/j.pain.0000000000000171

Nomura, D. K., Morrison, B. E., Blankman, J. L., Long, J. Z., Kinsey, S. G., Marcondes, M. C., Ward, A. M., Hahn Y. K., Lichtman A. H., Conti, B., \& Cravatt, B. F. (2011). Endocannabinoid Hydrolysis Generates Brain Prostaglandins That Promote Neuroinflammation. Science, 334(6057), 809-813. doi:10.1126/science.1209200

Rainsford, K. (1999). Profile and mechanisms of gastrointestinal and other side effects of nonsteroidal anti-inflammatory drugs (NSAIDs). The American Journal of Medicine, 107(6), 27-35. doi:10.1016/s0002-9343(99)00365-4

Reggio, P. (2010). Endocannabinoid Binding to the Cannabinoid Receptors: What Is Known and What Remains Unknown. Current Medicinal Chemistry, 17(14), 1468-1486. doi:10.2174/092986710790980005

Richardson, D., Pearson, R. G., Kurian, N., Latif, M. L., Garle, M. J., Barrett, D. A., Kendall, D. A., Scammell B. E., Reeve, A. J., \& Chapman, V. (2008). Characterization of the 
cannabinoid receptor system in synovial tissue and fluid in patients with osteoarthritis and rheumatoid arthritis. Arthritis Research \& Therapy, 10(2). doi:10.1186/ar2401

Rinaldi-Carmona, M., Barth, F., Millan, J., Derocq, J. M., Casellas, P., Congy, C., Oustric, D., Sarran, M., Shire, D., Breliere, J. C., \& Le Fur, G. L. (1998). SR144528, the first potent and selective antagonist of the CB2 cannabinoid receptor. Journal of Pharmacology and Experimental Therapeutics, 284(2), 644-650.

Rioja, I., Bush, K. A., Buckton, J. B., Dickson, M. C., \& Life, P. F. (2004). Joint cytokine quantification in two rodent arthritis models: Kinetics of expression, correlation of mRNA and protein levels and response to prednisolone treatment. Clinical \& Experimental Immunology, 137(1), 65-73. doi:10.1111/j.1365-2249.2004.02499.x

Robinson, R. H., Meissler, J. J., Fan, X., Yu, D., Adler, M. W., \& Eisenstein, T. K. (2015). A CB2-Selective Cannabinoid Suppresses T-Cell Activities and Increases Tregs and IL-10. Journal of Neuroimmune Pharmacology, 10(2), 318-332. doi:10.1007/s11481-015-96113

Russo, E. (2008). Cannabinoids in the management of difficult to treat pain. Therapeutics and Clinical Risk Management, 4, 245-259. doi:10.2147/tcrm.s1928

Savinainen, J. R., Kansanen, E., Pantsar, T., Navia-Paldanius, D., Parkkari, T., Lehtonen, M., Laitinen, T., Nevalainen, T., Poso, A., Levonen, A. L., \& Laitinen, J. T. (2014). Robust Hydrolysis of Prostaglandin Glycerol Esters by Human Monoacylglycerol Lipase (MAGL). Molecular Pharmacology, 86(5), 522-535. doi:10.1124/mol.114.094284 
Singh, S., Kaur, R., \& Sidhu, P. (2016). What failed BIA 10-2474 Phase I clinical trial? Global speculations and recommendations for future Phase I trials. Journal of Pharmacology and Pharmacotherapeutics, 7(3), 120. doi:10.4103/0976-500x.189661

Sokka, T., Kankainen, A., \& Hannonen, P. (2000). Scores for functional disability in patients with rheumatoid arthritis are correlated at higher levels with pain scores than with radiographic scores. Arthritis \& Rheumatism, 43(2), 386. doi:10.1002/15290131(200002)43:2<386::aid-anr19>3.0.co;2-z

Thiolat, A., Semerano, L., Pers, Y. M., Biton, J., Lemeiter, D., Portales, P., Quentin, J., Jorgenson, C., Decker, P., Boissier, M. C., Louis-Plence, P., \& Bessis, N. (2014). Interleukin-6 Receptor Blockade Enhances CD39 Regulatory T Cell Development in Rheumatoid Arthritis and in Experimental Arthritis. Arthritis \& Rheumatology, 66(2), 273-283. doi:10.1002/art.38246

Wilkerson, J. L., Ghosh, S., Bagdas, D., Mason, B. L., Crowe, M. S., Hsu, K. L., Wise, L. E., Kinsey, S. G., Damaj, M. I., Cravatt, B. F., \& Lichtman, A. H. (2016). Diacylglycerol lipase $\beta$ inhibition reverses nociceptive behaviour in mouse models of inflammatory and neuropathic pain. British Journal of Pharmacology, 173(10), 1678-1692. doi:10.1111/bph.13469

Yuan, M., Kiertscher, S. M., Cheng, Q., Zoumalan, R., Tashkin, D. P., \& Roth, M. D. (2002). $\Delta 9$-Tetrahydrocannabinol regulates $\mathrm{Th} 1 / \mathrm{Th} 2$ cytokine balance in activated human $\mathrm{T}$ cells. Journal of Neuroimmunology, 133(1-2), 124-131. doi:10.1016/s0165-5728(02)00370-3

Zhu, M., Yu, B., Bai, J., Wang, X., Guo, X., Liu, Y., Lin, J., Hu, S., Zhang, W., Tao, Y., Hu, C., Hang, H., Xu, Y., \& Geng, D. (2018). Cannabinoid receptor 2 agonist prevents local and 
systemic inflammatory bone destruction in rheumatoid arthritis. Journal of Bone and Mineral Research. doi:10.1002/jbmr.3637

\section{Acknowledgements}

I want to thank my advisor, Dr. Steven Kinsey, for his mentorship and support. I would also like to thank my thesis committee and lab mates (Kristen Trexler, Matthew Eckard, and Sara Nass) for the training and guidance I received over the course of my thesis project. Finally, I would like to thank my parents, Floyd and Nancy Steele. This project was supported financially by the National Institutes of Health [R15 AR066806]. 